\title{
O ENSINO DE CIÊNCIAS PARA ALUNOS COM DEFICIÊNCIA VISUAL: IDENTIFICANDO LIMITES E POSSIBILIDADES POR MEIO DE UMA REVISÃO SISTEMÁTICA DA LITERATURA
}

\section{SCIENCE EDUCATION FOR STUDENTS WITH VISUAL IMPAIRMENT: IDENTIFYING LIMITS AND POSSIBILITIES THROUGH A SYSTEMATIC LITERATURE REVIEW}

\author{
Halanda de Matos Mariano ${ }^{1}$ \\ Geraldo Wellington Rocha Fernandes ${ }^{2}$ \\ Raquel Schwenck de Mello Viana Soares ${ }^{3}$
}

\begin{abstract}
Resumo: Este trabalho tem o objetivo de caracterizar as pesquisas em ensino de Ciências referentes aos alunos com deficiência visual. Trata-se de uma pesquisa com abordagem qualitativa, através de uma revisão sistemática de trabalhos publicados em eventos nacionais e periódicos da área de ensino de Ciências com Qualis Capes A1/A2. O instrumento de análise dos dados foi a Análise Textual Discursiva (ATD). Os resultados foram divididos em duas partes. A primeira buscou caracterizar o levantamento bibliográfico dos trabalhos publicados em ensino de Ciências sobre alunos com deficiências visuais. A segunda parte caracteriza os limites e possibilidades sobre esta temática, através de quatro categorias emergentes: 1) Inclusão e o ensino de Ciências; 2) Formação de professores de Ciências e deficiência visual; 3) Construção, uso ou análise de materiais didáticos adaptados para alunos com deficiência visual no ensino de Ciências; e 4) Reflexões epistêmicas no ensino de Ciências para alunos com deficiência visual.
\end{abstract}

Palavras-chave: Deficiência Visual; Baixa Visão; Ensino de Ciências; Educação Inclusiva.

Abstract: This work aims to characterize research in science education related to students with visual impairment. This is a research with a qualitative approach, through a systematic review of works published in national events and journals in the field of science teaching with Qualis Capes A1/A2. The data analysis instrument was the Textual Discursive Analysis (TDA). The results were divided into two parts. The first sought to characterize the bibliographic survey of works published in science teaching about students with visual impairments. The second part characterizes the limits and possibilities on this theme, through four emerging categories: 1) Inclusion and the science teaching; 2) Training of science teachers and visual impairment; 3) Construction, use or analysis of didactic materials adapted for students with visual impairments in science teaching; and 4) Epistemic reflections on science teaching for visually impaired students.

Keywords: Visual impairment; Low vision; Science education; Inclusive education.

${ }^{1}$ Licencianda em Ciências Biológica pela Universidade Federal dos Vales do Jequitinhonha e Mucuri (UFVJM), Diamantina, MG, Brasil. E-mail: mariano.halanda@ufvjm.edu.br.

${ }^{2}$ Doutor em Educação em Ciências pela Universidade de Lisboa, Portugal (UL). Professor adjunto no Departamento de Ciências Biológicas da Universidade Federal dos Vales do Jequitinhonha e Mucuri (UFVJM), Diamantina, MG, Brasil. E-mail: geraldo.fernandes@ufvjm.edu.br.

${ }^{3}$ Doutora em Educação pela Universidad Católica de Santa Fé; Argentina (UCSF). Professora na Faculdade Interdisciplinar em Humanidades da Universidade Federal dos Vales do Jequitinhonha e Mucuri (UFVJM), Diamantina, MG, Brasil. E-mail: quelschwenck@ hotmail.com. 
DOI: https://doi.org/10.33238/ReBECEM.2021.v.5.n.2.27192

\section{Introdução}

A discussão acerca da inclusão de pessoas com deficiência no Brasil tornou-se mais aguerrida e fortalecida a partir dos anos 1990, com a promulgação da lei 9.394/ 96 que estabelece as Diretrizes e Bases da Educação Nacional (LDBEN). Esta, em seu capítulo V, apresenta o conceito da Educação Especial como sendo "a modalidade de educação escolar oferecida preferencialmente na rede regular de ensino, para educandos com deficiência, transtornos globais do desenvolvimento e altas habilidades ou superdotação" (BRASIL, 1996, p. 8).

Antes da LDBEN, as discussões sobre a educação formal de pessoas com deficiência eram orientadas sob a ótica da segregação e da integração, de uma maneira especializada com foco nas escolas especiais e profissionais, altamente específicos para cada tipo de deficiência, trazendo consigo a determinante da deficiência como déficit, numa visão clínica da mesma (OLIVEIRA, 2018).

Segundo a Convenção sobre os Direitos das Pessoas com Deficiência na ONU em 2006, ratificada no Brasil com status de emenda constitucional, por meio dos decretos $\mathrm{n}^{\circ}$ 186/2008 e nº 6.949/2009, "Pessoas com deficiência são aquelas que têm impedimentos de longo prazo de natureza física, mental, intelectual ou sensorial, os quais, em interação com diversas barreiras, podem obstruir sua participação plena e efetiva na sociedade em igualdades de condições com as demais pessoas" (BRASIL, 2009, p. 16).

Em específico a este grupo de pessoas com deficiência sensorial, estão os indivíduos com deficiência visual (DV), sendo caracterizada, no documento supracitado como:

Perda total ou parcial de visão, congênita ou adquirida, variando o nível ou a
acuidade visual da seguinte forma: Cegueira: acuidade visual igual ou menor
que 0,05 no melhor olho, com a melhor correção óptica; ausência total de visão
até a perda de percepção luminosa. Baixa visão: acuidade visual entre 0,3 e
0,05 no melhor olho, com a melhor correção óptica; os casos nos quais a
somatória da medida do campo de visão em ambos os olhos for igual ou menor
que $60^{\circ}$; ou a ocorrência simultânea de quaisquer das condições anteriores
(BRASIL, 2009, p. 22 ).

Assim, serão consideradas neste estudo, as pessoas com DV, os alunos/ estudantes que são cegos ou com baixa visão (BV). Nesta lógica, segundo Gonçalves et al. (2013), o ensino de Ciências para alunos com DV, no Brasil, ainda passa por dificuldades, 


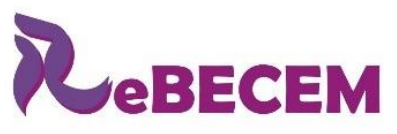

Revista Brasileira de Educação em

Ciências e Educação Matemática

DOI: https://doi.org/10.33238/ReBECEM.2021.v.5.n.2.27192

principalmente no que se refere à aprendizagem dos estudantes. Esta dificuldade pode ser ocasionada, além da falta de materiais didáticos, também pela formação de professores, que muitas vezes não estão preparados para trabalhar com alunos com deficiência, o que pode levar a não inclusão deles no ambiente escolar. Os mesmos autores explicitam que o professor é concebido como peça-chave do processo de ensino, sendo culpabilizado pelo sucesso ou fracasso do estudante. No entanto, é importante esclarecer que uma preparação adequada de todo pessoal da educação é um fator importante no progresso em direção às escolas inclusivas (BRASIL, 2005). O trabalho de Oliveira (2018) confirma o estudo de Gonçalves et al. (2013) ao apresentar os resultados de um levantamento nacional sobre a produção e utilização de recursos didáticos táteis adaptados a alunos com DV, além de analisar a percepção dos professores de Ciências e Biologia sobre o ensino e o uso de materiais adaptados. O que se verifica é que a produção de materiais ganhou força nos últimos anos, mesmo assim, ainda há subáreas dentro das Ciências da Natureza em que não são produzidos materiais. Em relação aos professores, Oliveira (2018) indica que ainda há muito despreparo e insegurança em relação ao ensino para alunos com DV, que não estão aptos para trabalhar com esses alunos, e que é necessária uma formação continuada para melhorar a educação inclusiva.

A partir desses apontamentos iniciais, este trabalho tem o objetivo de analisar e caracterizar os artigos publicados em revistas e anais de eventos nacionais em ensino de Ciências, por meio de uma revisão sistemática da literatura brasileira, com o intuito de responder a seguinte pergunta: Como se caracterizam as pesquisas em ensino de Ciências sobre deficiência visual? Queremos apresentar um panorama geral e atual sobre o que se tem publicado em relação ao ensino de Ciências para alunos com DV, uma vez que não foi possível identificar na literatura estudos que aprofundam esta temática.

Para responder à questão proposta, esta revisão tem como objetivos específicos: 1) caracterizar o quantitativo de trabalhos nos principais periódicos e anais de congressos em ensino de Ciências sobre deficiência visual; e 2) verificar como se caracterizam os principais estudos em ensino de Ciências sobre deficiência visual.

Pesquisas desse porte são de suma importância para a educação científica e para as políticas inclusivas do Brasil, pois elas são capazes de identificar os empecilhos vivenciados nas escolas, principalmente no que diz respeito à educação inclusiva no ensino de Ciências. Também se justifica por expor trabalhos que apresentam e analisam recursos didáticos, estratégias metodológicas adequadas e coerentes, além de apresentar 
reflexões sobre o ensino de Ciências para alunos/ estudantes com DV (cegos ou com baixa visão).

\section{Fundamentação Teórica}

\subsection{Educação especial e a formação de professores}

A formação de professores no Brasil, numa perspectiva inclusiva, passou a ser alvo de investimentos e formação específica a partir do final da década de 1990 com as legislações educacionais voltadas para uma perspectiva menos clínica das deficiências. Nesta perspectiva, a Resolução CNE/CP n 1/2002 (BRASIL, 2002a), que estabelece as Diretrizes Curriculares Nacionais para a Formação de Professores da Educação Básica, define que as instituições de ensino superior devem prever, em sua organização curricular, formação docente voltada para a atenção à diversidade e que contemple conhecimentos sobre as especificidades dos estudantes com deficiência, transtornos globais do desenvolvimento e altas habilidades/ superdotação.

Neste mesmo caminho, a Portaria $\mathrm{n}^{\circ}$ 2.678/02 do MEC aprova diretrizes e normas para o uso, o ensino, a produção e a difusão do sistema Braille em todas as modalidades de ensino, compreendendo o projeto da Grafia Braille para a Língua Portuguesa e a recomendação para o seu uso em todo o território nacional (BRASIL, 2002b). Em 2003, é implementado pelo MEC o Programa Educação Inclusiva: direito à diversidade, com vistas a apoiar a transformação dos sistemas de ensino em sistemas educacionais inclusivos, promovendo um amplo processo de formação de gestores e educadores nos municípios brasileiros para a garantia do direito de acesso de todos à escolarização, à oferta do atendimento educacional especializado e à garantia da acessibilidade.

Além destas, outras legislações específicas a cada tipo de deficiência foram criadas e promulgadas pelo governo federal com vistas à capacitação de profissionais para lidarem com o público-alvo da Educação Especial numa perspectiva inclusiva. Sendo estas pensadas com vistas ao atendimento da pessoa com deficiência nas escolas regulares comuns e não nas escolas especiais.

De acordo com Profeta (2007), é necessário que o professor compreenda que a inclusão favorece o aprendizado de todos, não somente do estudante, sendo lamentável que, na maioria das escolas, prevaleçam as práticas exclusivistas. $\mathrm{O}$ primeiro passo para 


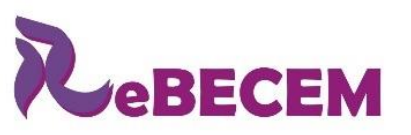

Revista Brasileira de Educação em

Ciências e Educação Matemática

DOI: https://doi.org/10.33238/ReBECEM.2021.v.5.n.2.27192

a transformação deste quadro é a formação dos professores, seja ela inicial, para licenciandos, ou continuada para professores atuantes na educação básica.

\subsection{Educação especial e o ensino de Ciências}

Em relação ao ensino dos conteúdos curriculares obrigatórios, a própria LDBEN preconiza a necessidade de se modificarem os métodos de ensino e de buscar recursos específicos que favoreçam o aprendizado, atendendo às diferentes necessidades dos alunos com algum tipo de deficiência. A LDBEN dedica um capítulo à Educação Especial e orienta, em seu artigo 59, que:

Os sistemas de ensino assegurarão aos educandos com deficiência, transtornos
globais do desenvolvimento e altas habilidades ou superdotação: I -
currículos, métodos, técnicas, recursos educativos e organização específicos,
para atender às suas necessidades [...] (BRASIL, 1996, on-line).

Dessa maneira, nota-se que a própria LDBEN demonstra preocupação com os métodos, estratégias e recursos educacionais a serem utilizados no ensino. Neste caminho de adaptações dos conteúdos curriculares obrigatórios, está o ensino de Ciências, sendo este considerado um conteúdo extremamente visual com aspectos da vida cotidiana. No que tange ao ensino de Ciências, a Unesco destaca: "para que um país esteja em condições de satisfazer as necessidades fundamentadas da sua população, o ensino das ciências e da tecnologia é um imperativo estratégico" (UNESCO, 1999, p. 5). Segundo Oliveira (2018), o ensino de Ciências para alunos com deficiência exige dos educadores bastante agilidade para despertar a atenção dos alunos e construir o seu conhecimento, uma vez que envolve o uso de imagens, símbolos e muita imaginação. Para isso, faz-se necessária a adaptação com descrições de textos, imagens, esquemas e outros para acessibilidade total dos materiais utilizados em sala de aula.

\subsection{Ensino de Ciências para alunos deficientes visuais (cegos ou baixa visão)}

Entende-se que ser professor é fazer com que o aluno entre em contato com o conhecimento científico e faça dele uma possível ferramenta capaz de mudar a sua percepção de mundo. Desta maneira, acredita-se ser de fundamental importância sua formação frente à política da inclusão, na busca por uma prática pedagógica que respeite as diferenças presentes na sala de aula (SILVA; ARRUDA, 2014). Neste sentido, é 
DOI: https://doi.org/10.33238/ReBECEM.2021.v.5.n.2.27192

importante que o professor seja capaz de receber e ensinar os estudantes com deficiência, pois é um agente modificador da realidade deste público.

Nesta perspectiva inclusiva, quando o professor proporciona aos alunos com DV diferentes formas de acesso ao conteúdo escolar, por meio do veículo que lhe permite contemplar o mundo, respeitando o tempo necessário para tal, ele cria condições favoráveis à aprendizagem, proporcionando-lhes igualdade de condições com outros alunos (REILY, 2004).

No que se faz referência ao ensino das Ciências da Natureza e suas Tecnologias, é necessário que a utilização de materiais concretos esteja presente, durante o ensino, para possibilitar ao educando com DV a possibilidade de compreender o conteúdo (OLIVEIRA, 2018). O que há de ser feito é a adaptação de alguns materiais e utilização de recursos didáticos que instiguem e possibilitem a aprendizagem significativa e a equidade entre os estudantes. Para isso, já são utilizados alguns recursos como: escrita Braille, caixa de números, fita métrica adaptada, figuras em alto relevo, sistemas operacionais (Dosvox, Virtual Vision), modelos tridimensionais, maquetes etc. (SÁ; CAMPOS; SILVA, 2007).

Para a aplicação de estratégias e recursos didáticos aos alunos com DV, é fundamental que haja formação continuada para os professores de Ciências e demais profissionais da educação, contribuindo para o aprimoramento do trabalho docente. Também é fundamental favorecer a criação de novos ambientes de aprendizagem, que conduzem docentes e discentes em direção a práticas pedagógicas capazes de ressignificar a aprendizagem (OLIVEIRA, 2018). É possível constatar que o ensino de Ciências, para estudantes com DV, está intimamente relacionado com o uso de materiais didáticos táteis adaptados e a formação de professores, uma vez que os docentes são importantes para o processo educacional desse público, assim como o uso de estratégias e interação social entre os próprios alunos.

\section{Metodologia}

Para o desenvolvimento desta pesquisa, utilizou-se da abordagem qualitativa (LÜDKE; ANDRÉ, 1986), cujo objetivo foi de realizar um levantamento bibliográfico de trabalhos publicados (em formato eletrônico e/ou impresso) em eventos e periódicos da área de ensino de Ciências com a temática "ensino de Ciências para alunos com DV". 
DOI: https://doi.org/10.33238/ReBECEM.2021.v.5.n.2.27192

Para a análise dos trabalhos publicados em eventos, foram consideradas as edições do Encontro Nacional da Pesquisa em Ensino de Ciências - ENPEC (1997 a 2019), Encontro Nacional de Ensino de Biologia - ENEBio (2012 a 2018), Encontro Nacional de Ensino de Física - EPEF (1994 a 2018) e Encontro Nacional de Ensino de Química ENEQ (1982 a 2018).

A pesquisa bibliográfica nos quatro eventos nacionais buscou abranger trabalhos que abordassem o ensino de Ciências para alunos com DV em todos os níveis de ensino. Tais eventos ocorrem de dois em dois anos, e suas submissões podem ser em forma de texto de trabalho completo ou resumo expandido para pôster, ressaltando que nessa pesquisa foram usados apenas trabalhos completos. Nos sites de ambos os eventos, estão disponíveis templates para submissão de trabalhos. O Quadro 1 ilustra os anos investigados dos respectivos eventos na área de ensino de Ciências.

\begin{tabular}{|l|l|}
\hline Eventos & Edições das Atas \\
\hline ENPEC & $1997,1999,2001,2003,2005,2007,2009,2011,2013,2015,2017,2019$. \\
\hline EPEF & $1994,1996,1998,2000,2002,2004,2006,2008,2010,2011,2012,2014,2016,2018$. \\
\hline \multirow{2}{*}{ ENEQ } & $\begin{array}{l}1982,1984,1986,1988,1990,1992,1994,1996,1998,2000,2002,2004,2006,2010,2012, \\
\end{array}$ \\
\hline ENEBio & $2014,2016,2018$. \\
\hline
\end{tabular}

Quadro 1. Anos investigados dos respectivos eventos da área de ensino de Ciências.

Fonte: Elaborado pelos autores (2021).

A pesquisa nos principais periódicos em ensino de Ciências obedeceu às seguintes condições: a) periódicos que se apresentavam na classificação do Quadriênio 2013-2016 da CAPES, referente ao Ensino de Ciências com Qualis A1/A2; e b) periódicos que apresentassem a temática pesquisada até o ano completo de 2019. Assim, os periódicos selecionados para análise foram: Revista Química Nova na Escola, Revista Ciência \& Educação, Alexandria, Revista Ensaio - Pesquisa em Educação em Ciências, Revista Brasileira de Pesquisa em Educação em Ciências, Caderno Brasileiro de Ensino de Física, Investigação em Ensino de Ciências, Revista Brasileira de Ensino de Física (RBEF). Outras revistas de ensino de Ciências que estão incluídas no extrato Qualis de ensino A1/A2 não foram consideradas nesta pesquisa por não apresentarem trabalhos referentes à temática "ensino de Ciências para Deficientes Visuais", a exemplo dos periódicos: Revista Brasileira de Ensino de Ciência e Tecnologia, Revista de Ensino de Ciências e Matemática (RENCIMA), entre outras.

Inicialmente, o levantamento de artigos nos anais dos congressos e periódicos em ensino de Ciências foi realizado através da análise dos títulos e palavras-chave. Com isso, 


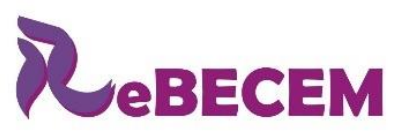

Revista Brasileira de Educação em

Ciências e Educação Matemática

DOI: https://doi.org/10.33238/ReBECEM.2021.v.5.n.2.27192

foram usados os termos de busca: 1) deficiência visual, 2) deficientes visuais, e 3) baixa visão, para identificar e selecionar os trabalhos que fizeram parte da presente pesquisa. Para um segundo recorte, foram lidos os resumos de todos os trabalhos escolhidos, buscando encontrar respostas para os objetivos da pesquisa.

Dessa forma, tem-se como corpus de análise os resumos, tanto dos trabalhos publicados em periódicos, quanto em eventos. Contudo, em algumas situações, foi necessária a análise completa do texto. Vale ressaltar que, os trabalhos apresentados em forma de pôster só foram selecionados quando estavam acompanhados do texto completo, caso contrário não seriam utilizados na presente pesquisa.

A partir dos trabalhos selecionados, levou-se em consideração a caracterização das informações relacionadas ao ensino de Ciências com alunos que têm alguma DV.

Ao final do levantamento bibliográfico e da leitura dos escritos, foi realizada a Análise Textual Discursiva (ATD) de Moraes e Galiazzi (2011). A ATD foi escolhida pelo fato de valorizar os detalhes das informações que surgem no decorrer da pesquisa, podendo produzir outros significados existentes por meio da análise textual do corpus. Desse modo, a partir dessa ferramenta de análise metodológica, tem-se a oportunidade de analisar o surgimento de diferentes categorias e subcategorias.

A partir da ATD, foi possível perceber a presença de unidades de significados que caracterizavam o ensino de Ciências para alunos com DV, bem como os métodos usados pelos professores em sala de aula, os quais tinham o intuito de melhorar a forma de compreensão dos conteúdos de Ciências.

Posteriormente, depois de uma segunda leitura, essa mais detalhada, foi realizada a unitarização da produção textual, a partir dos escritos publicados em periódicos e eventos, originando uma reorganização das unidades de sentido. Estas foram organizadas por semelhanças e disponibilizadas em quatro categorias emergentes ou a posteriori:

1) Inclusão e o ensino de Ciências: compreende os trabalhos que tem como foco central a inclusão dos alunos com alguma DV nas aulas de Ciências;

2) Formação de professores e o ensino de Ciências para alunos com DV: abrange os textos que ressaltam a formação dos professores e a caracterização do ensino de Ciências;

3) Construção, uso ou análise de materiais didáticos adaptados para alunos com DV no ensino de Ciências: apresenta os escritos que apontam o uso, a construção e a análise de materiais didáticos adaptados para que ocorra alguma forma de interação e inclusão dos alunos em sala de aula. 
DOI: https://doi.org/10.33238/ReBECEM.2021.v.5.n.2.27192

4) Reflexões epistêmicas no ensino de Ciências para alunos com DV: tem-se nessa categoria os estudos que buscaram relacionar, estudar e observar as percepções e concepções sobre os conteúdos de Ciências, temas relacionados à natureza da Ciência e ao processo de construção de conhecimento dos alunos com alguma DV.

Dando sequência, a partir do próximo tópico, serão apresentados os resultados encontrados e discussões das categorias em forma de metatextos (MORAES; GALIAZZI, 2011), com a finalidade de responder ao problema de pesquisa citado no início do texto.

\section{Resultados e Discussão}

Os resultados que serão apresentados foram divididos em duas partes. A primeira é a caracterização do quantitativo dos trabalhos publicados, relativo ao ensino de Ciências para alunos com DV. A segunda é a discussão das categorias que emergiram dos trabalhos analisados no decorrer dos anos, com a finalidade de compreender 'o que' e 'como' tem se estudado e pesquisado a respeito da temática em nível nacional.

\subsection{Análise do quantitativo de trabalhos em relação ao ensino de Ciências para alunos com algum tipo de DV}

A Tabela 1 apresenta a disposição dos trabalhos selecionados em cada encontro e periódico. Não foi possível identificar, dentro de cada evento e de cada volume dos periódicos, o total de trabalhos publicados.

Tabela 1: Disposição dos trabalhos encontrados em eventos e periódicos de ensino de Ciências.

\begin{tabular}{|c|c|c|}
\hline Eventos & Período & $\begin{array}{ll}\mathbf{N}^{\circ} & \text { de } \\
\text { Trabalhos }\end{array}$ \\
\hline $\begin{array}{l}\text { Encontro Nacional de Pesquisa em Educação em } \\
\text { Ciências }\end{array}$ & $1997-2019$ & 32 \\
\hline Encontro Nacional de Pesquisa em Ensino de Física & $1994-2018$ & 14 \\
\hline $\begin{array}{l}\text { Encontro Nacional de Pesquisa em Ensino de } \\
\text { Química }\end{array}$ & $1982-2018$ & 14 \\
\hline $\begin{array}{l}\text { Encontro Nacional de Pesquisa em Ensino de } \\
\text { Biologia }\end{array}$ & $2012-2018$ & 21 \\
\hline Total em Eventos & & 81 \\
\hline Periódicos & $\begin{array}{l}\text { Volumes analisados até } \\
2019\end{array}$ & $\begin{array}{ll}\mathbf{N}^{\circ} & \text { de } \\
\text { Trabalhos } & \\
\end{array}$ \\
\hline Revista Química Nova na Escola & 01 a 41 & 04 \\
\hline Revista Ciência \& Educação & 01 a 25 & 05 \\
\hline Revista Ensaio - Pesquisa em Educação em Ciências & 01 a 21 & 04 \\
\hline
\end{tabular}


DOI: https://doi.org/10.33238/ReBECEM.2021.v.5.n.2.27192

Continuação.

\begin{tabular}{l|l|l}
\hline Alexandria Revista de Educação em Ciências e Tecnologia & 01 a 12 & 01 \\
\hline Revista Brasileira de Pesquisa em Educação em Ciências & 01 a 19 & 06 \\
\hline Investigações em Ensino de Ciências & 01 a 24 & 03 \\
\hline Caderno Brasileiro de Ensino de Física & 01 a 36 & 01 \\
\hline Revista Brasileira de Ensino de Física & 01 a 41 & 02 \\
\hline Total em Periódicos & & $\mathbf{2 6}$ \\
\hline Total em eventos e periódicos & & $\mathbf{1 0 7}$ \\
\hline
\end{tabular}

Fonte: Elaborada pelos autores (2021).

É possível verificar, na Tabela 1, um total de 107 trabalhos sobre o tema ensino de Ciências para alunos com DV. Os trabalhos encontrados apresentaram pesquisas que abrangeu apenas os estudantes com DV. Não era objetivo deste estudo identificar trabalhos que abordassem o professor sendo deficiente visual. A maioria dos escritos foram identificados nos eventos e em menor número nos periódicos. Este resultado se justifica pelo fato de os encontros nacionais abrangerem uma maior quantidade de pesquisadores como: professores de programas de pós-graduação, ensino superior e da educação básica, alunos de graduação e pós-graduação, dentre outros, quando comparados com os periódicos pesquisados. Ao analisar individualmente os anais de cada encontro e periódico, percebe-se uma baixa produção de pesquisas que refletem o tema pesquisado. Ao verificar os anais dos congressos e os periódicos, a produção total é bastante significativa, porém o quantitativo de 107 trabalhos encontrados é muito baixo em relação à produção total, ao longo dos anos, das pesquisas divulgadas nos eventos e periódicos da Tabela 1 .

Dando sequência, a Tabela 2 apresenta a quantidade dos escritos encontrados em cada um dos ENPECs e que citam a temática pesquisada.

Tabela 2: Quantidade de trabalhos encontrados nos ENPECs.

\begin{tabular}{l|l}
\hline ENPECs & Número de Trabalhos Encontrados \\
\hline $\begin{array}{l}\text { I ENPEC (1997)/ II ENPEC (1999)/ } \\
\text { III ENPEC (2001) }\end{array}$ & 0 \\
\hline IV ENPEC (2003) & 01 \\
\hline V ENPEC (2005) & 03 \\
\hline VI ENPEC (2007) & 03 \\
\hline VII ENPEC (2009) & 04 \\
\hline VIII ENPEC (2011) & 06 \\
\hline IX ENPEC (2013) & 01 \\
\hline X ENPEC (2015) & 01 \\
\hline XI ENPEC (2017) & 07 \\
\hline XII ENPEC (2019) & 06 \\
\hline Total de Trabalhos & $\mathbf{3 2}$ \\
\hline
\end{tabular}

Fonte: Elaborada pelos autores (2021). 
DOI: https://doi.org/10.33238/ReBECEM.2021.v.5.n.2.27192

$\mathrm{Na}$ Tabela 2, pode-se observar que nos primeiros anos do ENPEC não havia publicações sobre a temática, só a partir de 2003 (IV ENPEC) que surge a primeira publicação, o que mostra a evolução do interesse em pesquisar sobre o tema. É no ENPEC que se encontra a maioria da produção sobre a temática $(39,5 \%)$ e $29,9 \%$ de toda a produção, incluindo os periódicos. Mesmo com a evolução das publicações, em comparação com o volume total de trabalhos apresentados nos ENPECs, a temática ainda é pouco pesquisada e divulgada (OLIVEIRA, 2018).

Ao analisar os EPEFs, a partir da Tabela 3, tem-se o número de trabalhos encontrados, porém a pesquisa em ensino de Física/Ciências que relaciona ao aluno com DV e o ensino de Ciências ainda é baixa.

Tabela 3: Quantidade de trabalhos encontrados nos EPEFs.

\begin{tabular}{l|l}
\hline EPEFs & $\begin{array}{l}\text { Número de Trabalhos } \\
\text { Encontrados }\end{array}$ \\
\hline $\begin{array}{l}\text { I EPEF/ II EPEF/ III EPEF/ IV EPEF (1994)/ V EPEF (1996)/ VI EPEF } \\
\text { (1998)/ VII EPEF (2000)/ XII EPEF (2010)/ XIII EPEF (2012)/ XIV EPEF } \\
\text { (2014) }\end{array}$ & 0 \\
\hline VIII EPEF (2002) & 01 \\
\hline IX EPEF (2004) & 01 \\
\hline X EPEF (2006) & 02 \\
\hline XI EPEF (2008) & 02 \\
\hline XV EPEF (2016) & 01 \\
\hline XVI EPEF (2018) & 07 \\
\hline Total de Trabalhos & $\mathbf{1 4}$ \\
\hline
\end{tabular}

Fonte: Elaborada pelos autores (2021).

Não foi possível analisar as três primeiras edições do EPEF, uma vez que não foram encontrados os anais e as páginas online dos encontros, porém, nas edições seguintes, a Tabela 3 indica uma quantidade baixa no número de publicações, quando comparada com a quantidade de eventos já realizados e com o número de trabalhos encontrados nos ENPECs. Isso mostra mais uma vez, a falta que se tem de publicações ligadas a essa temática, principalmente no ensino de Física/ Ciências.

Em relação aos ENEQs, a Tabela 4 apresenta o quantitativo de trabalhos publicados com a temática pesquisada, principalmente no ensino de Química/ Ciências.

Tabela 4: Quantidade de trabalhos encontrados nos ENEQs.

\begin{tabular}{c|c}
\hline \multicolumn{1}{c|}{ ENEQs } & $\begin{array}{c}\text { Número de } \\
\text { Trabalhos } \\
\text { Encontrados }\end{array}$ \\
\hline I ENEQ (1982)/ II ENEQ (1984)/ III ENEQ (1986)/ IV ENEQ (1988)/ V ENEQ & \\
(1990)/ VI ENEQ (1992)/ VII ENEQ (1994)/ VIII ENEQ (1996)/ IX ENEQ & 0 \\
$(1998) /$ X ENEQ (2000)/ XI ENEQ (2002)/ XII ENEQ (2004)/ XIV ENEQ & \\
$(2008) /$ XVII ENEQ (2014) & \\
\hline
\end{tabular}

Continua. 
DOI: https://doi.org/10.33238/ReBECEM.2021.v.5.n.2.27192

\begin{tabular}{l|l}
\hline XIII ENEQ (2006) & 01 \\
\hline XV ENEQ (2010) & 04 \\
\hline XVI ENEQ (2012) & 03 \\
\hline XVIII ENEQ (2016) & 04 \\
\hline XIX ENEQ (2018) & 02 \\
\hline Total de Trabalhos & $\mathbf{1 4}$ \\
\hline
\end{tabular}

Fonte: Elaborada pelos autores (2021).

Observa-se na Tabela 4 que as publicações relacionadas com a temática da pesquisa foram apresentadas em edições mais recentes, que começaram a partir do XIII ENEQ, em 2006, ressaltando que, em alguns anos anteriores, os trabalhos ou as páginas dos encontros não estavam disponíveis para visualização. Também é possível verificar que os ENEQs também apresentam uma baixa produção, igualmente quando comparado com os EPEFs, uma vez que este encontro iniciou em 1982 (19 eventos em 36 anos).

Por último, a Tabela 5 apresenta a quantidade de artigos encontrados nas edições do ENEBio.

Tabela 5: Quantidade de trabalhos encontrados nos ENEBio.

\begin{tabular}{l|l}
\hline ENEBio & Número de Trabalhos Encontrados \\
\hline I ENEBIO (2005)/ II ENEBIO (2007)/ IV ENEBIO (2012) & 0 \\
\hline III ENEBIO (2010) & 01 \\
\hline V ENEBIO (2014) & 06 \\
\hline VI ENEBIO (2016) & 06 \\
\hline VII ENEBIO (2018) & 08 \\
\hline Total de Trabalhos & $\mathbf{2 1}$ \\
\hline
\end{tabular}

Fonte: Elaborada pelos autores (2021).

$\mathrm{Na}$ Tabela 5, pode-se verificar que ocorreu uma concentração de publicações de trabalhos nas três últimas edições, com um total de 21 artigos. Verifica-se, também, uma escassez de pesquisas no ensino de Biologia/ Ciências sobre o tema em questão, uma vez que os eventos recebem muitos trabalhos. Não é possível dizer com certeza o porquê desse número tão baixo de publicações acerca do tema nas sete primeiras edições do ENEBio.

Por fim, ao olhar para toda a produção identificada nos periódicos e eventos em ensino de Ciências (Tabelas 1 a 5), verifica-se que a produção é pulverizada ao longo dos anos e somente a partir dessa última década que começou a surgir uma maior concentração dos trabalhos que relacionam o ensino de Ciências e a DV (Gráfico 1). 
DOI: https://doi.org/10.33238/ReBECEM.2021.v.5.n.2.27192

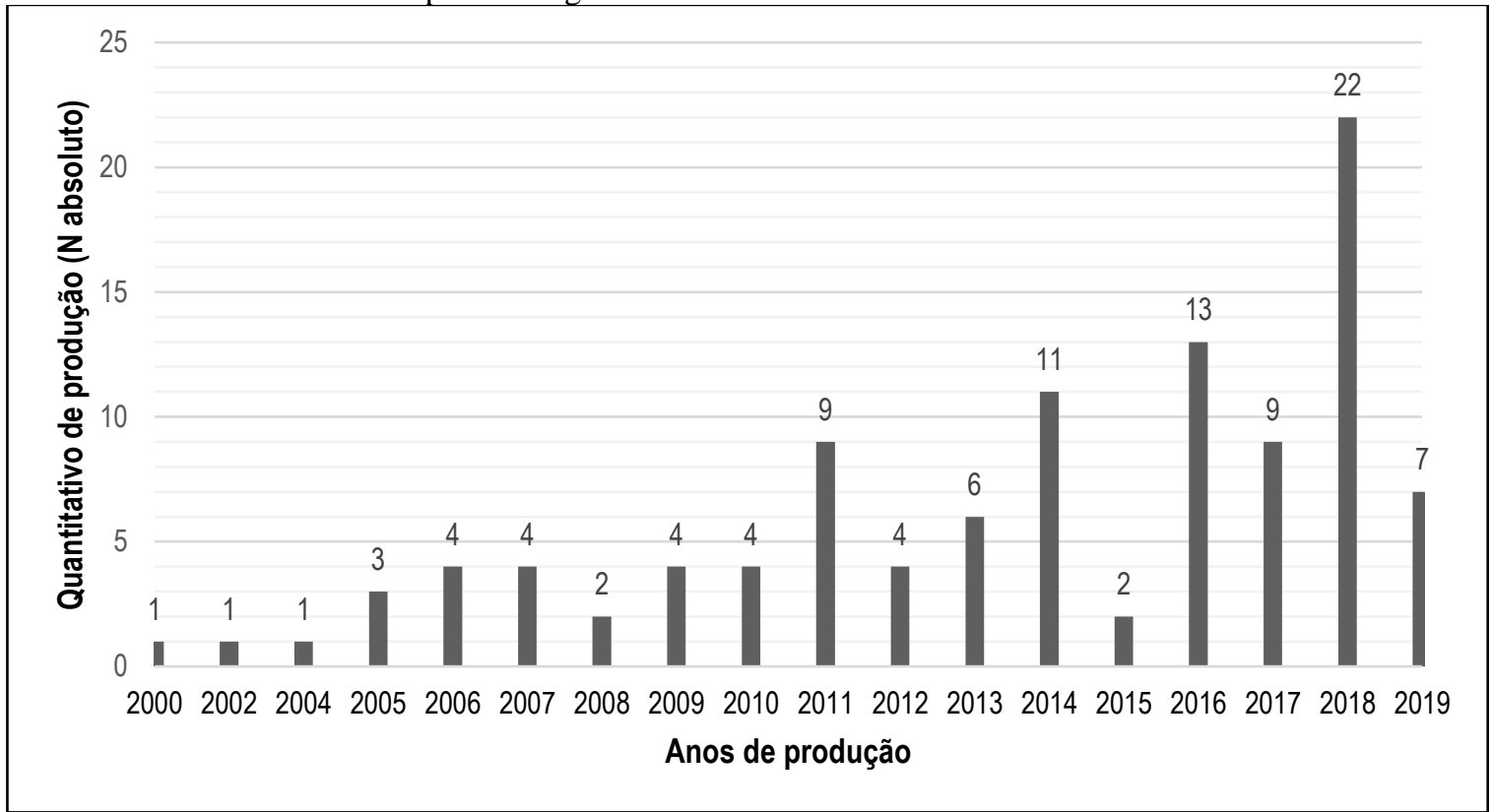

Gráfico 1. Quantitativo dos trabalhos em ensino de Ciências e DV por anos de produção em periódicos e eventos.

Fonte: Elaborado pelos autores (2021).

Esperava-se um número maior de publicações nos eventos e periódicos, uma vez que as leis para o ensino inclusivista deram-se a partir de 1996 com a LDBEN e a temática já deveria estar sendo discutida nos cursos de formação de professores.

\subsection{Análise das categorias emergentes}

A partir da análise do corpus da pesquisa (os resumos e/ou textos completos) por meio da ATD, foi possível organizar as unidades de significado em categorias emergentes e que estão apresentadas na Tabela 6 com o número de trabalhos envolvidos. No decorrer dos resultados, serão apresentadas e analisadas as categorias, seguidas da quantidade e referência dos trabalhos selecionados para esta pesquisa.

Tabela 6. Categorias emergentes e número de trabalhos.

\begin{tabular}{l|l|l}
\hline $\mathbf{N}$ & Categorias & $\begin{array}{l}\mathbf{N}^{\mathbf{o}} \\
\text { Trabalhos }\end{array}$ \\
\hline 1 & Inclusão e o ensino de Ciências & 21 \\
\hline 2 & Formação de professores e o ensino de Ciências para alunos com DV & 24 \\
\hline 3 & $\begin{array}{l}\text { Construção, uso ou análise de materiais didáticos adaptados para alunos com DV } \\
\text { no ensino de Ciências }\end{array}$ & 41 \\
\hline 4 & Reflexões epistêmicas no ensino de Ciências para alunos com DV & 21 \\
\hline TOTAL & $\mathbf{1 0 7}$ \\
\hline
\end{tabular}

Fonte: Elaborada pelos autores (2021). 


\section{Categoria 1: Inclusão e o ensino de Ciências}

Essa categoria emergiu a partir da análise dos trabalhos que discutem a inclusão de alunos com DV nas escolas e nas aulas de Ciências. A pesquisa identificou um total de 21 publicações que se adequaram à essa categoria, o que indica uma baixa periodicidade de artigos voltados para a inclusão de alunos com DV no ensino de Ciências. Com isso, é possível perceber um certo distanciamento da pesquisa em EC sobre a inclusão de pessoas ou alunos com DV.

Segundo Pacheco e Costas (2006), a formação docente é um dos maiores empecilhos para discutir e aplicar a inclusão no contexto escolar, apontando que a maioria dos professores adquire conhecimentos e formação, relacionados aos alunos com deficiência, só a partir do momento em que se encontram na sala de aula. Na Tabela 7 encontram-se as principais pesquisas relacionadas a essa categoria.

Tabela 7: Artigos selecionados conforme a categoria "Inclusão e o Ensino de Ciências".

\begin{tabular}{|c|c|c|}
\hline $\mathbf{N}$ & Título dos artigos & Anais ou Revista \\
\hline 1 & $\begin{array}{l}\text { REGIANI, A. M.; SOUZA, G. Inclusão de uma aluna cega em um } \\
\text { curso de licenciatura em Química. }\end{array}$ & $\begin{array}{l}\text { Ciência \& Educação, v. 19, } \\
\text { n. 1, p. 123-134, 2013. }\end{array}$ \\
\hline 2 & $\begin{array}{l}\text { NUNES, B. C.; et al. Propostas de atividades experimentais } \\
\text { elaboradas por futuros professores de química para alunos com } \\
\text { deficiência visual. }\end{array}$ & XV ENEQ (2010) \\
\hline 3 & $\begin{array}{l}\text { ARAGÃO, A. S.; SILVA, G. M. Reflexões de uma licencianda em } \\
\text { química sobre a inclusão escolar de alunos com deficiência visual. }\end{array}$ & XV ENEQ (2010) \\
\hline 4 & $\begin{array}{l}\text { SANTOS, G. A.; MÓL, G. S. Construindo páginas na web para o } \\
\text { ensino de química acessível a deficientes visuais. }\end{array}$ & XVIII ENEQ (2016) \\
\hline 5 & $\begin{array}{l}\text { CAMARGO, E. P.; SANTOS, S. L. R.; NARDI, R.; VERASZTO, } \\
\text { E. V. Alunos com deficiência visual em um curso de química: } \\
\text { fatores atitudinais como dificuldades educacionais. }\end{array}$ & VI ENPEC (2007) \\
\hline 6 & $\begin{array}{l}\text { CAMARGO, E. P.; NARDI, R.; LIPPE, E. M. O. A comunicação } \\
\text { como barreira à inclusão de alunos com deficiência visual em aulas } \\
\text { de termologia. }\end{array}$ & VII ENPEC (2009) \\
\hline 7 & $\begin{array}{l}\text { LIMA, M. C. de A. B.; MACHADO, M. A. D. As representações } \\
\text { sociais dos licenciandos de física referentes à inclusão de } \\
\text { deficientes visuais. }\end{array}$ & $\begin{array}{l}\text { Revista Ensaio: Pesquisa em } \\
\text { Educação em Ciências. v.13, } \\
\text { n.03, p.119-131, 2011 }\end{array}$ \\
\hline 8 & $\begin{array}{l}\text { BORGES, J.; SILVA, E. S.; SANTOS, Z. O ensino da lei de Lenz } \\
\text { adaptado para a deficiência visual: um experimento com circuito } \\
\text { oscilador. }\end{array}$ & XI EPEF (2008) \\
\hline 9 & $\begin{array}{l}\text { FIORINI, M. L. S.; DELIBERATO, D.; MANZINI, E. J. } \\
\text { Estratégias de ensino para alunos deficientes visuais: a proposta } \\
\text { curricular do Estado de São Paulo. }\end{array}$ & $\begin{array}{l}\text { Revista Ensaio: Pesquisa em } \\
\text { Educação em Ciências. v. } \\
\text { 19, n. 1, p. } 62-73,2013\end{array}$ \\
\hline 10 & $\begin{array}{l}\text { DUARTE, A. C. S. Aprendizagem de ciências naturais por } \\
\text { deficientes visuais: um caminho para inclusão. }\end{array}$ & V ENPEC (2005) \\
\hline 11 & $\begin{array}{l}\text { LIBARDI, H.; PEDROSO, A. P.; MENDES, T. P.; BRAZ, F. F.; } \\
\text { OLIVEIRA, G. A. de. PIBID e a educação inclusiva de alunos com } \\
\text { deficiência visual: materiais manipulativos e linguagem } \\
\text { matemática para o ensino de ciências. }\end{array}$ & VIII ENPEC (2011) \\
\hline
\end{tabular}

Continua. 
Continuação.

\begin{tabular}{|c|c|c|}
\hline 12 & $\begin{array}{l}\text { CARVALHO et al. Uma proposta do uso do computador como } \\
\text { ferramenta inclusiva de deficientes visuais em aulas de física. }\end{array}$ & VIII ENPEC (2011) \\
\hline 13 & $\begin{array}{l}\text { QUADROS, L.; NOVAES, T.; LIBARDI, D.; RABBI, M. A.; } \\
\text { FERRACIOLI, L. Construção da tabela periódica e modelo físico } \\
\text { do átomo para pessoas com deficiência visual. }\end{array}$ & VIII ENPEC (2011) \\
\hline 14 & $\begin{array}{l}\text { DRESCHER, C. F.; OLIVEIRA, J. S.; FERNANDES, L. da S. } \\
\text { Bingo químico em braille. }\end{array}$ & XVI ENEQ (2012) \\
\hline 15 & $\begin{array}{l}\text { SILVA, M. R.; CAMARGO, E. P. O uso do braille por alunos } \\
\text { cegos: dificuldades e outras implicações para o processo de ensino } \\
\text { e aprendizagem de Física. }\end{array}$ & XI ENPEC (2017) \\
\hline 16 & $\begin{array}{l}\text { SILVA, M. R.; CAMARGO, E. P. A inclusão de alunos com } \\
\text { deficiência visual em cursos de graduação em Física: algumas } \\
\text { dificuldades e contribuições do atendimento educacional } \\
\text { especializado. }\end{array}$ & XVII EPEF (2018) \\
\hline 17 & $\begin{array}{l}\text { LEAL, M. C. R. Educação Ambiental como um instrumento de } \\
\text { inclusão no ensino de Biologia. }\end{array}$ & V ENEBIO (2014) \\
\hline 18 & $\begin{array}{l}\text { VERONA, M. F.; LOPES, M. B. O ensino de Ciências e Biologia } \\
\text { para pessoas com deficiência visual / cegos: uma análise } \\
\text { fundamentada no XI ENPEC. }\end{array}$ & VII ENEBIO (2018) \\
\hline 19 & $\begin{array}{l}\text { ANDRADE, J. A. M. de; PAGAN, A. A. Inclusão no ensino } \\
\text { superior: estudo de caso de uma licencianda com deficiência do } \\
\text { curso de Biologia. }\end{array}$ & VII ENEBIO (2018) \\
\hline 20 & $\begin{array}{l}\text { SILVA, M. R; CAMARGO, E. P. O Atendimento Pedagógico } \\
\text { Especializado E O Ensino De Física: Uma Investigação Acerca Do } \\
\text { Processo De Ensino E Aprendizagem De Uma Aluna Cega. }\end{array}$ & $\begin{array}{l}\text { Revista Ens. Pesqui. Educ. } \\
\text { Ciênc., Belo Horizonte, v. } \\
\text { 20, e2894, } 2018\end{array}$ \\
\hline 21 & $\begin{array}{l}\text { DA SILVA, M. D.; GONÇALVES, F. P.; MARQUES, C. A. } \\
\text { Práticas pedagógicas em Ciências da Natureza nos anos iniciais do } \\
\text { ensino fundamental com estudantes cegos. }\end{array}$ & $\begin{array}{l}\text { Revista Brasileira de } \\
\text { Pesquisa em Educação em } \\
\text { Ciências, v. 15, n. 3, p. 497- } \\
\text { 518, 2015. }\end{array}$ \\
\hline
\end{tabular}

Fonte: elaborada pelos autores (2021).

Dentre os 21 trabalhos encontrados, é possível identificar várias propostas e estratégias de inclusão. Inicialmente, verifica-se um grupo de trabalhos que discute o uso de recursos didáticos como forma de inclusão, por exemplo, o trabalho (N14) que sugere o uso de um jogo (bingo em Braille) para promover a inclusão de alunos com DV em uma aula de Química. O trabalho de Quadros et al (2011) (N13), buscou realizar a construção de uma tabela periódica em Braille e o modelo de um átomo que seria aplicado para estudantes cegos. Já no trabalho N1 é desenvolvido a inclusão de uma aluna cega em um curso de Química. Por meio de um questionário aplicado à turma onde aconteceu a inclusão da aluna cega, a maioria apontou a escassez de materiais didáticos adaptados para as aulas de Ciências.

Outro grupo de estudos propõe estratégias de ensino de Ciências como forma de inclusão, por exemplo, o trabalho N9 alerta sobre a importância da comunicação verbal para a aprendizagem, pois através dela, os estudantes com DV têm acesso aos componentes da linguagem, por meio das exposições orais apresentadas em sala de aula. 


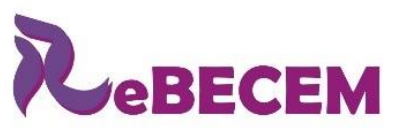

Revista Brasileira de Educação em

Ciências e Educação Matemática

DOI: https://doi.org/10.33238/ReBECEM.2021.v.5.n.2.27192

Essas estratégias, e outras da Tabela 7, apresentam a finalidade de promover a inclusão de alunos que apresentem DV e as de outros tipos, além de garantir um ensino de Ciências de qualidade.

Contudo, mesmo com a identificação de diversas estratégias de ensino e elaboração de recursos que possam auxiliar à inclusão dos estudantes no ensino de Ciências (Tabela 7), verifica-se que as publicações, nessa categoria, não aprofundam o “como ocorre" e o "que é" esse processo de inclusão.

A educação inclusiva para Pacheco et al. (2007): “[...] pressupõe que a escola se ajuste a todas as crianças que desejam matricular-se em sua localidade, em vez de esperar que uma determinada criança com necessidades especiais se ajuste à escola [...]” (p. 13). Sendo assim, um professor inclusivista é aquele que se ajusta a seus alunos com algum tipo de deficiência, em nosso caso, visual, e planeja suas aulas às necessidades especiais deste aluno.

Nenhum estudo da Tabela 7 apresenta uma análise sobre o que diz a Base Nacional Comum Curricular (BNCC) sobre o ensino de Ciências para alunos com DV. Se este documento tem intenção de estabelecer, em âmbito nacional, um "currículo mínimo" a ser seguido e cumprido pelas instituições de ensino da Educação Básica, de modo a proporcionar um ensino de qualidade a todos os estudantes (BRASIL, 2018), não se encontra profundas mudanças sobre a educação inclusiva para alunos com DV, a não ser por um parágrafo que apresenta a natureza dessa modalidade de ensino, no item referente a BNCC e a "igualdade, diversidade e equidade": "Igualmente, requer o compromisso com os alunos com deficiência, reconhecendo a necessidade de práticas pedagógicas inclusivas e de diferenciação curricular, conforme estabelecido na Lei Brasileira de Inclusão da Pessoa com Deficiência (Lei no 13.146/2015)" (BRASIL, 2018, p. 16). A BNCC não contempla o processo de desenvolvimento e aprendizagem dos estudantes com DV, uma vez que não há ações e objetivos voltados ao aprendizado deles.

Compreender o que esta categoria apresenta é muito mais que incluir estudantes com DV no ensino de Ciências, exige repensar sobre o conceito de "inclusão" na educação básica e no ensino superior, uma vez que esta reflexão carece de discussões. Entende-se que o preparo e a capacitação de professores da educação básica e ensino superior, além de diferentes profissionais da educação se fazem necessários.

A inclusão dos estudantes com DV no ensino de Ciências deve ser compreendida como um processo em construção que envolve reflexões, tentativas, acertos, erros etc. e que transcende a sala de aula. Portanto, a sistematização e o compartilhamento de 


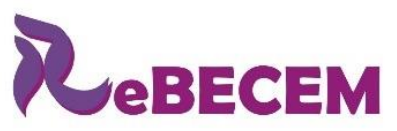

\section{Revista Brasileira de Educação em \\ Ciências e Educação Matemática}

DOI: https://doi.org/10.33238/ReBECEM.2021.v.5.n.2.27192

informações para a inclusão desses alunos nas aulas e no ensino de Ciências podem contribuir para a troca de experiências entre profissionais da educação, possibilitando adequações e reflexões sobre tal processo.

\section{Categoria 2: Formação de professores e o ensino de Ciências para alunos com DV}

Essa categoria faz referência à formação dos professores para ensinar e incluir alunos com DV no ensino de Ciências. Para essa categoria, foram encontrados 24 estudos que relacionaram a formação de professores de Ciências e o ensino para alunos com DV. Ao analisar os trabalhos, pode-se verificar que alguns estudos estavam voltados para a educação básica, atingindo professores dos ensinos Fundamental e Médio, que muitas vezes não se encontram preparados para lidar com público que necessita de cuidados especiais (GONÇALVES et al., 2013).

Além disso, os estudos dessa categoria indicam a relação que o currículo tem com a forma que o professor trabalha em sala de aula, principalmente quando se trata de algum aluno com DV. Os trabalhos da Tabela 8 também indicam que, muitas vezes, o currículo, no qual o educador realiza sua graduação, não enfatiza a educação inclusiva, formando assim, profissionais despreparados em lidar com educandos com DV (por exemplo, N2 e N5 da Tabela 8). Assim, a Tabela 8 apresenta a organização dos trabalhos que fazem parte dessa categoria.

Tabela 8: Artigos selecionados de acordo com a categoria "Formação de professores de Ciências e alunos com DV".

\begin{tabular}{c|l|l}
\hline $\mathbf{N}$ & \multicolumn{1}{|c}{ Título dos artigos } & \multicolumn{1}{|c}{ Anais ou Revista } \\
\hline 1 & $\begin{array}{l}\text { GONÇALVES, F. P. et al. A educação inclusiva na formação de } \\
\text { professores e no ensino de química: deficiência visual em debate. }\end{array}$ & $\begin{array}{l}\text { Revista Química nova na } \\
\text { escola. v. 35, n 4, p. 264- } \\
271,2013\end{array}$ \\
\hline 2 & $\begin{array}{l}\text { LIMA, M. C. B.; CASTRO, G. F. A formação inicial de } \\
\text { professores de física: a questão de alunos com deficiência visual } \\
\text { no ensino regular. }\end{array}$ & $\begin{array}{l}\text { Revista Ciência \& } \\
\text { Educação. v. 18, n. 1, p. 81- } \\
98,2012\end{array}$ \\
\hline 3 & $\begin{array}{l}\text { LIMA, M. C. A. B.; GONÇALVES, C. O. O ensino não formal } \\
\text { de um professor de física para deficientes visuais. }\end{array}$ & $\begin{array}{l}\text { Revistas Ensaio: Pesquisa } \\
\text { em Educação em Ciências. } \\
\text { v.16, n. 02, p. 167-183, 2014 }\end{array}$ \\
\hline 4 & $\begin{array}{l}\text { BENITE, A. M. C. et al. O diário virtual coletivo: um recurso } \\
\text { para investigação dos saberes docentes mobilizados na formação } \\
\text { de professores de química de deficientes visuais. }\end{array}$ & $\begin{array}{l}\text { Revista Química nova na } \\
\text { escola. v. 36, n. 1, p. 61-70, } \\
2014\end{array}$ \\
\hline 5 & $\begin{array}{l}\text { PAULA, T. E.; GUIMARÃES O. M.; SILVA, C. S. da. } \\
\text { Formação de professores de química no contexto da educação } \\
\text { inclusiva. }\end{array}$ & $\begin{array}{l}\text { Alexandria Revista de } \\
\text { Educação em Ciências e } \\
\text { Tecnologia. v. 11, n. 1, p. 3- } \\
29,2018\end{array}$ \\
\hline
\end{tabular}

Continua. 
Continuação.

\begin{tabular}{|c|c|c|}
\hline 6 & $\begin{array}{l}\text { BATISTA, M. A. R. S. et al. O diário virtual coletivo: um recurso } \\
\text { para investigação da formação de professores de ciências de } \\
\text { deficientes visuais. }\end{array}$ & VIII ENPEC (2011) \\
\hline 7 & $\begin{array}{l}\text { AGUIAR, M. V. F.; LIMA, M. C. A. Como pensam os } \\
\text { professores de física de um colégio público em relação ao ensino } \\
\text { de física para deficientes visuais. }\end{array}$ & VIII ENPEC (2011) \\
\hline 8 & $\begin{array}{l}\text { LIMA, M. C. B.; MACHADO, M. A. D.; CATARINO, G. F. C. } \\
\text { Aprender a lecionar física para deficientes visuais. }\end{array}$ & XV EPEF (2014) \\
\hline 9 & $\begin{array}{l}\text { VERASZTO, E. V.; CAMARGO, J. T. F.; CAMARGO, E. P. de. } \\
\text { Trabalho científico por cegos congênitos: análise das respostas de } \\
\text { licenciandos em cursos da área de ciências da natureza. }\end{array}$ & XVI EPEF (2016) \\
\hline 10 & $\begin{array}{l}\text { CAMARGO, E. P.; VIVEIROS, E. R.; NARDI, R. Trabalhando } \\
\text { conceitos de ótica e eletromagnetismo com alunos com } \\
\text { deficiência visual e videntes. }\end{array}$ & X EPEF (2006) \\
\hline 11 & $\begin{array}{l}\text { CAMARGO, E. P.; NARDI, R. Um estudo sobre a formação do } \\
\text { professor de física no contexto das necessidades educacionais } \\
\text { especiais de alunos com deficiência visual. }\end{array}$ & X EPEF (2006) \\
\hline 12 & $\begin{array}{l}\text { SILVA, E. N.; SALGADO, A. H. I. O ensino de ciências para } \\
\text { alunos com deficiência visual. Estariam os professores } \\
\text { capacitados para lidar com esse público? }\end{array}$ & XI ENPEC (2017) \\
\hline 13 & $\begin{array}{l}\text { ROSS, J. D. T.; VOSS. I. C. O ensino de ciências da natureza } \\
\text { para estudantes cegos: uma análise nos anos iniciais do ensino } \\
\text { fundamental. }\end{array}$ & XI ENPEC (2017) \\
\hline 14 & $\begin{array}{l}\text { ALVES, B. C.; LIMA, M. C. B.; CATARINO, G. F. C. } \\
\text { Formação inicial de professores de física inclusivistas. }\end{array}$ & XI ENPEC (2017) \\
\hline 15 & $\begin{array}{l}\text { LIMA, M. C. B.; CATARINO, G. F. C. Formação inicial de } \\
\text { professores de física inclusivistas: interdisciplinaridade por si... }\end{array}$ & IX ENPEC (2013) \\
\hline 16 & $\begin{array}{l}\text { COSTA, L. G.; NEVES, M. C. D; BARONE, D. A. C. O ensino } \\
\text { de física para deficientes visuais a partir de uma perspectiva } \\
\text { fenomenológica. }\end{array}$ & $\begin{array}{l}\text { Revista Ciência \& } \\
\text { Educação. v. 12, n. 2, p. } \\
\text { 143-153, 2006 }\end{array}$ \\
\hline 17 & $\begin{array}{l}\text { MORRENE, W.; AMARAL, L. H.; ARAUJO, M. S. T. de. } \\
\text { Conceituando corrente e resistência elétrica por meio das } \\
\text { sensações humanas e percepções humanas: um experimento para } \\
\text { aprendizagem significativa de alunos deficientes visuais. }\end{array}$ & XI EPEF (2008) \\
\hline 18 & $\begin{array}{l}\text { SILVA, M. R.; CAMARGO, E. P. Os discursos de professores de } \\
\text { Física acerca de suas alunas cegas }\end{array}$ & XVII EPEF (2018) \\
\hline 19 & $\begin{array}{l}\text { JÚNIOR, A. J. V.; GOBARA, S. T. Ensino em modelos: } \\
\text { formação continuada de professores de Ciências e Biologia no } \\
\text { contexto da deficiência visual }\end{array}$ & XII ENPEC (2019) \\
\hline 20 & $\begin{array}{l}\text { MENEZES, J. B. F. et al. Educação inclusiva no ensino de } \\
\text { biologia: experiência no estágio supervisionado }\end{array}$ & VI ENEBIO (2016) \\
\hline 21 & $\begin{array}{l}\text { SILVA, C. A. de M.; IKETANI, C. Experiências e observações } \\
\text { de uma monitora durante o ensino inclusivo de genética básica na } \\
\text { graduação }\end{array}$ & VII ENEBIO (2018) \\
\hline 22 & $\begin{array}{l}\text { FILHO, A. C. M. et al. Dificuldades no ensino de Biologia para } \\
\text { alunos com deficiência no município de Capanema - PA }\end{array}$ & VII ENEBIO (2018) \\
\hline 23 & $\begin{array}{l}\text { CAMARGO, E. P.; NARDI, R. Dificuldades e alternativas } \\
\text { encontradas por licenciandos para o planejamento de atividades } \\
\text { de ensino de eletromagnetismo para alunos com deficiência } \\
\text { visual. }\end{array}$ & $\begin{array}{l}\text { Investigações em Ensino de } \\
\text { Ciências, v. 12, n. 2, } 2007 .\end{array}$ \\
\hline 24 & $\begin{array}{l}\text { DE PAULA, T. E.; GUIMARÃES, O. M.; SILVA, C. S. } \\
\text { Necessidades Formativas de Professores de Química para a } \\
\text { Inclusão de Alunos com Deficiência Visual. }\end{array}$ & $\begin{array}{l}\text { Revista Brasileira de } \\
\text { Pesquisa em Educação em } \\
\text { Ciências, v. 17, n. 3, p. 853- } \\
881,2017 .\end{array}$ \\
\hline
\end{tabular}

Fonte: Elaborada pelos autores (2021). 
DOI: https://doi.org/10.33238/ReBECEM.2021.v.5.n.2.27192

Por meio da análise dos trabalhos dessa categoria, foram identificadas diversas formas que buscam auxiliar o professor a ministrar aulas para alunos com DV, por exemplo: algumas experiências vivenciadas (por exemplo, N1, N2 e N3), elaborações de materiais e modelos didáticos pelos professores de Ciências (por exemplo, N10, N17 e N23) e reflexões sobre o papel do currículo na formação docente (por exemplo, N9, N15 e N24).

Os trabalhos que apresentam o papel do currículo na formação docente são de extrema importância para o ensino, pois de acordo com Lima e Castro (2012), a educação inclusivista deve se fazer presente desde a formação inicial do professor. Nesta perspectiva de formação, pode-se citar como exemplo, o trabalho N4, que utilizou um diário virtual coletivo, onde os professores compartilham suas experiências de investigação dos saberes docentes, em relação às aulas de Química para alunos com DV, e que apresenta as dificuldades que devem ser exploradas para garantir o melhor acesso à educação desses alunos. O trabalho N6 apresenta a mesma ideia do diário virtual coletivo, porém buscou investigar a formação dos professores de Ciências que desenvolvem ações para trabalhar com alunos com DV. Trabalhos como esses servem como possíveis exemplos e são muito importantes para o ensino de Ciências, pois auxiliam os professores a prepararem suas aulas, induzindo-os a usarem metodologias e recursos didáticos que buscam favorecer a formação dos alunos com DV.

No entanto, mesmo que a presente pesquisa tenha encontrado uma variedade de trabalhos que analisa alguns métodos, estratégias e recursos didáticos para alunos com DV, pensados para a formação de professores de Ciências, verifica-se, ainda, que a baixa quantidade de publicações, envolvendo essa categoria, indica que a temática pesquisada não vem sendo estudada com tanta frequência, mesmo sendo uma questão de profunda reflexão para a formação de professores.

Nesta mesma direção, ao olhar para o que diz as Diretrizes Curriculares Nacionais para a Formação Inicial de Professores para a Educação Básica e a Base Nacional Comum para a Formação Inicial de Professores da Educação Básica (BNC-Formação) (BRASIL, 2019) em relação ao processo de formação de professores para inclusão de estudantes com DV, não se encontra nenhuma orientação.

Para ampliar as discussões, se poderia pensar que os momentos de educação inclusiva devem ser propiciados durante a formação inicial dos licenciandos e continuada dos professores, tendo, por exemplo, o estágio supervisionado, o Programa Institucional 


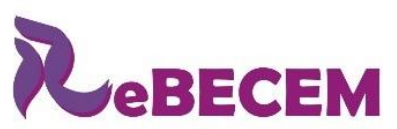

\section{Revista Brasileira de Educação em \\ Ciências e Educação Matemática \\ ISSN 2594-9179}

DOI: https://doi.org/10.33238/ReBECEM.2021.v.5.n.2.27192

de Bolsa à Iniciação à Docência (PIBID) e Residência Pedagógica (RP), como uma forma de observar, na prática, a rotina de uma turma, possuidora de alunos com DV, adaptando as aulas de Ciências, trazendo métodos e recursos condizentes com a realidade desses estudantes para que se possa efetivar uma formação inicial e continuada de qualidade para trabalhar a DV no ensino de Ciências.

\section{Categoria 3: Construção, uso ou análise de materiais didáticos adaptados para alunos com DV no ensino de Ciências}

Essa categoria apresenta a análise dos trabalhos que discutem, de alguma maneira, o papel dos materiais e recursos didáticos adaptados para alunos com DV nas aulas de Ciências. O uso dos diferentes tipos de materiais busca a inclusão escolar e a melhor formação educacional dos estudantes. Fazem parte dessa categoria 41 trabalhos e que estão organizados na Tabela 9.

Tabela 9: Artigos da categoria "Construção, uso ou análise de materiais didáticos adaptados para alunos com DV no ensino de Ciências".

\begin{tabular}{|c|c|c|}
\hline $\mathbf{N}$ & Título dos artigos & Anais ou Revista \\
\hline 1 & $\begin{array}{l}\text { FERNANDES, T. C.; HUSSEIN, F. R. G. S.; DOMINGUES, R. } \\
\text { C. P. R. Ensino de química para deficientes visuais: a importância } \\
\text { da experimentação num enfoque multissensorial. }\end{array}$ & $\begin{array}{l}\text { Revista Química nova na. V. } \\
\text { 39, n. 2, p. 195-203, } 2017\end{array}$ \\
\hline 2 & $\begin{array}{l}\text { BENITE, C. R. M. et al. A experimentação do ensino de química } \\
\text { para deficientes visuais como o uso de tecnologia assistiva: o } \\
\text { termômetro vocalizado. }\end{array}$ & $\begin{array}{l}\text { Revista Química nova na } \\
\text { escola. n. 39, n. 3, p. 245-249, } \\
2017\end{array}$ \\
\hline 3 & $\begin{array}{l}\text { FERRAZ, A. F. A. et al. Ciclo de vida das angiospermas: uma } \\
\text { proposta de material didático com contribuição ao ensino e } \\
\text { aprendizagem para deficientes visuais. }\end{array}$ & VI ENEBIO (2016) \\
\hline 4 & $\begin{array}{l}\text { FERNANDES, A. F. de F.; LAGE, D. de A. Inclusão escolar no } \\
\text { ensino de biologia: elaboração de materiais adaptados para } \\
\text { deficientes visuais e auditivos. }\end{array}$ & VI ENEBIO (2016) \\
\hline 5 & $\begin{array}{l}\text { LIAÑO G. de A.; SANTOS, L. D. dos; VARANDA, L. L. A } \\
\text { genética ao alcance das mãos: confecção e utilização de modelos } \\
\text { táteis para a inclusão de alunos com deficiência visual no ensino } \\
\text { regular. }\end{array}$ & VI ENEBIO (2016) \\
\hline 6 & $\begin{array}{l}\text { ANDRADE, D. P. de; LACHEL, G. Elaboração de recursos } \\
\text { didáticos para o ensino de astronomia para deficientes visuais. }\end{array}$ & XI ENPEC (2016) \\
\hline 7 & $\begin{array}{l}\text { SILVA, P. R. da; RUST, N. M. O ensino de ciências: produção de } \\
\text { material didático para alunos cegos e com baixa visão. }\end{array}$ & VI ENEBIO (2016) \\
\hline 8 & $\begin{array}{l}\text { PINTO, D. da C. et al. A construção de minimuseus de ciências } \\
\text { auxiliando deficientes visuais no ensino fundamental, médio e } \\
\text { superior no estado do Rio de Janeiro, Brasil. }\end{array}$ & V ENPEC (2005) \\
\hline 9 & $\begin{array}{l}\text { BRITO, L. G. de F.; SILVA, M. G. L. da. A tabela periódica: um } \\
\text { recurso para a inclusão de alunos com deficiência visual. }\end{array}$ & V ENPEC (2005) \\
\hline
\end{tabular}

Continua. 
Continuação.

\begin{tabular}{|c|c|c|}
\hline 10 & $\begin{array}{l}\text { CAMARGO, E. P.; SILVA, D. Atividade e material didático para } \\
\text { o ensino de física à alunos com deficiência visual: queda dos } \\
\text { objetos. }\end{array}$ & IX ENPEC (2013) \\
\hline 11 & $\begin{array}{l}\text { BATISTETI, C. B. et al. Uma discussão sobre a utilização da } \\
\text { história da ciência no ensino de célula para alunos com deficiência } \\
\text { visual. }\end{array}$ & VII ENPEC (2009) \\
\hline 12 & $\begin{array}{l}\text { PESSANHA, P. R. et al. Uma proposta para abordagem das leis } \\
\text { de Kepler em sala de aula de alunos com deficiência visual. }\end{array}$ & VII ENPEC (2009) \\
\hline 13 & $\begin{array}{l}\text { TATO, A. L.; LIMA, M. C. B. Material de equacionamento tátil } \\
\text { para portadores de deficiência visual. }\end{array}$ & VI ENPEC (2007) \\
\hline 14 & $\begin{array}{l}\text { FIELD'S, K. A. P. et al. Ensino de química para deficientes } \\
\text { visuais: sobre intervenção pedagógica em instituição de apoio. }\end{array}$ & XVI ENEQ (2012) \\
\hline 15 & $\begin{array}{l}\text { BELTRAMIN, F. S.; GÓIS, J. Materiais didáticos para alunos } \\
\text { cegos e surdos no ensino de química. }\end{array}$ & XVI ENEQ (2012) \\
\hline 16 & $\begin{array}{l}\text { ANDRADE, J. de. J. de; SMOLKA, A. L. B. Os sentidos da/na } \\
\text { experimentação no ensino: um estudo sobre o ensino de química } \\
\text { para crianças com baixa visão. }\end{array}$ & XIII ENEQ (2016) \\
\hline 17 & $\begin{array}{l}\text { PASSINATO, C. de B.; NETO, W. N. de A.; ALMEIDA, R. V. } \\
\text { Comparações entre imagens e suas áudio-descrições para } \\
\text { deficientes visuais em um livro didático de química. }\end{array}$ & XVIII ENEQ (2016) \\
\hline 18 & $\begin{array}{l}\text { PEDROSA, L. L.; GUIMARÃES, O. M. Os materiais didáticos } \\
\text { adaptados para deficientes visuais nas aulas de química na } \\
\text { perspectiva de alunos cegos, especialista e gestor educacional. }\end{array}$ & XVIII ENEQ (2016) \\
\hline 19 & $\begin{array}{l}\text { FOCHESATO, R. de A.; GUIMARÃES, O. M. Tendências das } \\
\text { pesquisas internacionais sobre o ensino de ciências para } \\
\text { deficientes visuais: foco nos materiais didáticos para ensino de } \\
\text { química. }\end{array}$ & XVIII ENEQ (2016) \\
\hline 20 & $\begin{array}{l}\text { CAMARGO, E. P. de; SILVA, D. da. O ensino de física para } \\
\text { alunos com deficiência visual: atividade que aborda a posição de } \\
\text { encontro de dois moveis por meio de um problema aberto. }\end{array}$ & IX EPEF (2004) \\
\hline 21 & $\begin{array}{l}\text { MORRONE, W.; ARAÚJO, M. S. T. de; AMARAL, L. H. } \\
\text { Analogias e experimentação em eletrodinâmica baseadas no } \\
\text { conhecimento sensível: um experimento para aprendizagem } \\
\text { significativa de alunos deficientes visuais. }\end{array}$ & VII ENPEC (2009) \\
\hline 22 & $\begin{array}{l}\text { FARIA, B. A. de. et al. Ensino de química para deficientes visuais } \\
\text { numa perspectiva inclusiva: estudo sobre o ensino da distribuição } \\
\text { eletrônica e identificação dos elementos químicos. }\end{array}$ & XI ENPEC (2017) \\
\hline 23 & $\begin{array}{l}\text { SILVEIRA, R. A. da; GONÇALVES, F. P. Compreensões sobre } \\
\text { cegueira e atividades experimentais no Ensino de Química: quais } \\
\text { as relações possíveis? }\end{array}$ & XIX ENEQ (2018) \\
\hline 24 & $\begin{array}{l}\text { VERASZTO, E. V., PIRES, B. M.; VICENTE, N. E. F.; NETO, } \\
\text { O. A. S. Desenvolvimento, aplicação e análise de atividades de } \\
\text { ensino de óptica para alunos cegos e com baixa visão }\end{array}$ & XVII EPEF (2018) \\
\hline 25 & $\begin{array}{l}\text { NUNES, M. M. et al. Ouvir e sentir estrelas: astronomia para } \\
\text { pessoas com deficiência visual }\end{array}$ & XVII EPEF (2018) \\
\hline 26 & $\begin{array}{l}\text { QUINTANILHA, L.; BARBOSA-LIMA; M. da C. Ensino de } \\
\text { Física através da patinação artística para alunos com deficiência } \\
\text { visual }\end{array}$ & XVII EPEF (2018) \\
\hline
\end{tabular}

Continua. 
Continuação.

\begin{tabular}{|c|c|c|}
\hline 27 & $\begin{array}{l}\text { FRANÇA, F. A. et al. O ensino de viscosidade no atendimento } \\
\text { educacional especializado para alunos deficientes visuais através } \\
\text { da experimentação }\end{array}$ & XII ENPEC (2019) \\
\hline 28 & $\begin{array}{l}\text { MONTEIRO, A. F. B. et al. Significando o conceito de atrito e } \\
\text { tração em rodas através da Teoria da Atividade de Vigotski e } \\
\text { Leontiev para crianças com Deficiência Visual }\end{array}$ & XII ENPEC (2019) \\
\hline 29 & $\begin{array}{l}\text { FERREIRA, G- K.; VOOS, I. C.; SANTOS, T. F. M. } \\
\text { Acessibilidade para estudantes cegos e baixa visão: uma análise } \\
\text { dos objetos educacionais digitais do Programa Nacional do Livro } \\
\text { Didático de Física }\end{array}$ & X ENPEC (2015) \\
\hline 30 & $\begin{array}{l}\text { OLIVEIRA, M. da S. G. et al. Fortalecedor de unhas: para o ensino } \\
\text { da solubilidade envolvendo alunos com deficiência visual }\end{array}$ & XII ENPEC (2019) \\
\hline 31 & $\begin{array}{l}\text { SILVA, E. J. da; VESTENA, R. de F. Sequência didática } \\
\text { inclusiva: percepção tátil e sistema átex mediando conteúdos na } \\
\text { construção de heredogramas }\end{array}$ & V ENEBIO (2014) \\
\hline 32 & $\begin{array}{l}\text { DUMS, M.; DIONOR, G. A.; LOPATIUK, M. M. Educação } \\
\text { Ambiental sob uma perspectiva inclusiva: proposta de sequências } \\
\text { didáticas. }\end{array}$ & V ENEBIO (2014) \\
\hline 33 & $\begin{array}{l}\text { PAULETTI, J. et al. Modelo didático tridimensional de epiderme } \\
\text { foliar como estratégia para inclusão de alunos com deficiência } \\
\text { visual no ensino de botânica }\end{array}$ & V ENEBIO (2014) \\
\hline 34 & $\begin{array}{l}\text { RANGEL, A.; OLIVEIRA, R. I. de. Flores de pano como modelo } \\
\text { didático para o ensino inclusivo de botânica }\end{array}$ & VII ENEBIO (2018) \\
\hline 35 & $\begin{array}{l}\text { MELO, L. B. et al. Livretato: uma ferramenta de instrução para } \\
\text { auxiliar o ensino de genética de forma lúdica e inclusiva através } \\
\text { do tato }\end{array}$ & VII ENEBIO (2018) \\
\hline 36 & $\begin{array}{l}\text { MORENO, G. de M.; CORDOVA, B. C.; OLIVEIRA, R. I. R. } \\
\text { Modelos de DNA, RNA e hemácias do sistema abo humanos para } \\
\text { ensino inclusivo de biologia }\end{array}$ & VII ENEBIO (2018) \\
\hline 37 & $\begin{array}{l}\text { NASCIMENTO, L. M. M.; BOCCHIGLIERI, A. Modelos } \\
\text { didáticos no ensino de Vertebrados para estudantes com } \\
\text { deficiência visual. }\end{array}$ & $\begin{array}{l}\text { Ciência \& Educação, v. 25, n. } \\
\text { 2, pp.317-332, } 2019\end{array}$ \\
\hline 38 & $\begin{array}{l}\text { VAZ, J. M. C.; PAULINO, A. L. de S.; BAZON, F. V. M.; KIILL, } \\
\text { K. B.; ORLANDO, T. C.; REIS, M. X. dos; MELLO, C. Material } \\
\text { Didático para Ensino de Biologia: Possibilidades de Inclusão. }\end{array}$ & $\begin{array}{l}\text { Revista Brasileira } \\
\text { Pesquisa em Educação em } \\
\text { Ciências, v. 12, n. 3, p. 81- } \\
\text { 104, 2013. }\end{array}$ \\
\hline 39 & $\begin{array}{l}\text { RIZZO, A. L.; BORTOLINI, S.; REBEQUE, P. V. dos S. Ensino } \\
\text { do Sistema Solar para alunos com e sem deficiência visual: } \\
\text { proposta de um ensino inclusivo. }\end{array}$ & $\begin{array}{l}\text { Revista Brasileira de } \\
\text { Pesquisa em Educação em } \\
\text { Ciências, v. 14, n. 1, p. 191- } \\
\text { 204, 2014. }\end{array}$ \\
\hline 40 & $\begin{array}{l}\text { CARVALHO, J. C. Q. et al. A linguagem átex e o ensino de Física } \\
\text { para alunos com deficiência visual. }\end{array}$ & $\begin{array}{l}\text { Investigações em Ensino de } \\
\text { Ciências, v. 23, n.2, } 2018 .\end{array}$ \\
\hline 41 & $\begin{array}{l}\text { SILVA, A. C. da; SANTOS, C. A. dos. Lâminas em alto-relevo } \\
\text { para ensinar fenômenos ondulatórios a deficientes visuais. }\end{array}$ & $\begin{array}{l}\text { Rev. Bras. Ensino Fís., v.40, } \\
\text { n. } 4,2018 .\end{array}$ \\
\hline
\end{tabular}

Fonte: Elaborada pelos autores (2021).

Essa categoria apresenta o maior número de trabalhos, comparado com as categorias anteriores, mas não significa que esta temática tem uma produção significativa em comparação à produção total dos eventos e periódicos e com as principais linhas de pesquisa da área em ensino de Ciências. Oliveira (2018) também fez um levantamento 


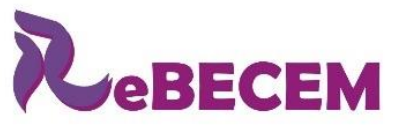

\section{Revista Brasileira de Educação em \\ Ciências e Educação Matemática}

DOI: https://doi.org/10.33238/ReBECEM.2021.v.5.n.2.27192

nacional sobre a produção e utilização dos recursos didáticos táteis adaptados a alunos com DV, para o ensino de Ciências e Biologia de 2000 a 2016. O que este autor observou foi que a produção foi crescendo, impulsionada principalmente nos anos de 2014 a 2016, mas mesmo com aumento dos estudos sobre o tema, a quantidade ainda não era significativa.

Para esta pesquisa, apesar de uma quantidade superior em relação às outras categorias, o Gráfico 2 indica que são poucos trabalhos encontrados, quando se analisa os anos que foram publicados, ou seja, mesmo que a partir de 2016 pode-se encontrar uma certa produção de trabalhos relacionados ao ensino de Ciências, alunos com DV e produção de materiais didáticos, não se pode afirmar que houve um crescimento da pesquisa acerca do tema.

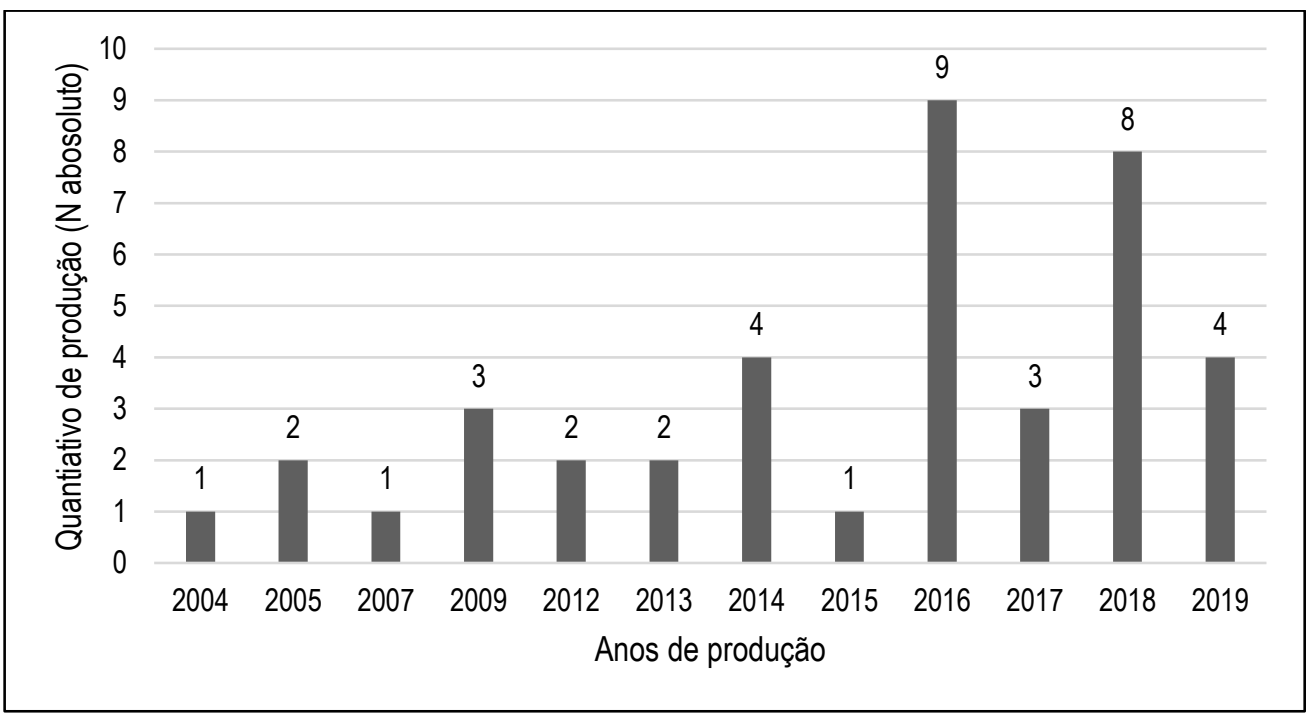

Gráfico 2. Quantitativo dos trabalhos sobre "Construção, uso ou análise de materiais didáticos adaptados para deficientes visuais no ensino de Ciências” por anos de produção em eventos e periódicos.

Fonte: Elaborado pelos autores (2021).

Ao analisar esses estudos, foi possível verificar alguns materiais didáticos possíveis de serem usados nas aulas de Ciências, por exemplo: termômetros vocalizados (N2), modelos táteis (N5 e N6) etc. A categoria conta com trabalhos que realizam a construção desses materiais, como na pesquisa de N3, e até trabalhos que analisam o uso deles, conforme o escrito de N5. Outra pesquisa que vale ressaltar é o N9 que apresenta uma tabela periódica dos elementos químicos e que estava adaptada às necessidades dos alunos com DV. Os autores realizaram uma entrevista com alunos para entender suas dificuldades com a tabela e como estava ocorrendo a inclusão dos estudantes cegos por meio da construção desse material. 


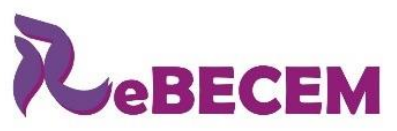

Revista Brasileira de Educação em

Ciências e Educação Matemática

DOI: https://doi.org/10.33238/ReBECEM.2021.v.5.n.2.27192

Quando se cria ou adapta um material recreativo ao conteúdo escolar, de acordo com Borges e Schwarz (2005), o indivíduo desenvolve habilidades de aspectos emocionais, relacionais e cognitivos.

É importante ressaltar a importância do uso de meios táteis no ensino de Ciências, uma vez que são formas viáveis de auxiliar os professores e garantir aos estudantes uma educação de melhor qualidade. Segundo Oliveira, Biz e Freire (2003), “A ausência da modalidade visual exige experiências alternativas de desenvolvimento, a fim de cultivar a inteligência e promover capacidades sócio adaptativas. O ponto central desses esforços é a exploração do pleno desenvolvimento tátil” (OLIVEIRA; BIZ; FREIRE, 2003, p. 446).

O que se percebe nos trabalhos da Tabela 9 é que existem preocupações em apresentar os diferentes recursos educacionais no ensino de Ciências, porém, poucos trabalhos trazem seus principais efeitos para o processo de aprendizagem dos alunos com DV. Também existe uma carência de trabalhos com referenciais teóricos significativos para a Categoria 3: construção, uso ou análise de materiais didáticos adaptados para alunos com DV no ensino de Ciências.

Observa-se uma ênfase nos materiais e recursos produzidos para um determinado conteúdo conceitual, nos relatos de experiências e nos limites e possibilidades de casos específicos. Neste sentido, tem-se que pensar se os professores da educação básica e ensino superior estão preparados para elaborar e usar esses recursos? Muitos materiais foram elaborados por licenciandos ou são provenientes de projetos como PIBID ou Estágio Supervisionado, mas os trabalhos não deixam claro a participação dos professores de Ciências.

Quando se analisa a aplicação dos diferentes materiais no ensino de Ciências, também se percebe que, na maioria das vezes, é realizada por licenciandos. Assim, essa categoria nos mostra que existe uma limitação e dificuldade dos professores da educação básica em elaborar e aplicar recursos educacionais para alunos com DV. Como superar tal dificuldade? Talvez a resposta estaria na "categoria 2", em que é importante repensar a formação de professores de Ciências em que leve em consideração, de uma maneira mais ativa, a categoria 1, ou seja, a "inclusão de estudantes com DV no ensino de Ciências". 


\section{Categoria 4: Reflexões epistêmicas no ensino de Ciências para alunos com DV}

Os trabalhos que caracterizam essa categoria, apresentados na Tabela 10, buscaram investigar as percepções e concepções dos alunos que possuem algum tipo de DV em relação a um certo conteúdo de Ciências, à natureza da Ciência e sobre o processo de ensino-aprendizagem. Com isso, 21 trabalhos foram responsáveis por emergir essa última categoria (Tabela 10).

Tabela 10: Artigos que caracterizam a categoria "Reflexões epistêmicas no ensino de Ciências para alunos com DV".

\begin{tabular}{|c|c|c|}
\hline $\mathbf{N}$ & Título dos artigos & Anais ou Revista \\
\hline 1 & $\begin{array}{l}\text { ANDRADE, J. de J. de. Conhecimento científico, conhecimento } \\
\text { cotidiano e a construção dos nexos nos processos de elaboração } \\
\text { conceitual. }\end{array}$ & XV ENEQ (2010) \\
\hline 2 & $\begin{array}{l}\text { ALVES, F. de S. et al. Concepções das pessoas com deficiência } \\
\text { visual sobre a Lua para produção de um material paradidático } \\
\text { adaptado. }\end{array}$ & XI ENPEC (2017) \\
\hline 3 & $\begin{array}{l}\text { DUARTE, A. C. S. et al. Percepções de alunos deficientes visuais } \\
\text { sobre educação ambiental. }\end{array}$ & VI ENPEC (2007) \\
\hline 4 & $\begin{array}{l}\text { VITORINO, D. A.; MIRANDA, A. G. de C. Conhecimentos } \\
\text { prévios de estudantes deficientes visuais sobre o corpo feminino } \\
\text { e masculino, sistemas genitais e puberdade. }\end{array}$ & VI ENEBIO (2016) \\
\hline 5 & $\begin{array}{l}\text { SANTOS, M. C. et al. As concepções alternativas dos deficientes } \\
\text { visuais no ensino de física. }\end{array}$ & VIII ENPEC (2011) \\
\hline 6 & $\begin{array}{l}\text { CAMARGO, E. P. de. O ensino de física e os portadores de } \\
\text { deficiência visual: aspectos da relação de suas concepções } \\
\text { alternativas de repouso e movimento com modelos históricos. }\end{array}$ & VIII EPEF (2002) \\
\hline 7 & $\begin{array}{l}\text { BONFIM, C. S.; NETO, H. da S. M. A elaboração de um guia } \\
\text { para investigar concepções de Natureza da Ciência }(\mathrm{NdC}) \text { de } \\
\text { educandos cegos }\end{array}$ & XIX ENEQ (2018) \\
\hline 8 & $\begin{array}{l}\text { VERASZTO, E. V. et al. Avaliação da compreensão do processo } \\
\text { de conceitualização em ciências por cegos congênitos }\end{array}$ & XVII EPEF (2018) \\
\hline 9 & $\begin{array}{l}\text { TELES, L. I. da S.; PORTELA, C. D. Possibilidades e reflexões } \\
\text { sobre o ensino de cores para estudantes cegos: percepções de } \\
\text { licenciandos do IFPR campus Paranaguá }\end{array}$ & XVII EPEF (2018) \\
\hline 10 & $\begin{array}{l}\text { PLAÇA, J. S. V.; GOBARA, S. T. O Ensino de Ciências para } \\
\text { alunos com baixa visão: a realidade da sala de aula na perspectiva } \\
\text { de um aluno }\end{array}$ & XII ENPEC (2019) \\
\hline 11 & $\begin{array}{l}\text { TELES, L. I. da S.; PORTELA, C. D. P. Os estudos sobre o ensino } \\
\text { de física para deficientes visuais }\end{array}$ & XII ENPEC (2019) \\
\hline 12 & $\begin{array}{l}\text { NUNES, V. H. C. et al. Dificuldades de portadores de deficiência } \\
\text { visual em sala de aula no ensino de ciências no ensino } \\
\text { fundamental }\end{array}$ & III ENEBIO (2010) \\
\hline 13 & $\begin{array}{l}\text { NOBRE, S. A. de O.; SILVA, F. R. F. Métodos e práticas do } \\
\text { ensino de Biologia para jovens especiais na escola de ensino } \\
\text { médio Liceu de Iguatu Dr. José Gondim, Iguatu/CE }\end{array}$ & V ENEBIO (2014) \\
\hline 14 & $\begin{array}{l}\text { TEODORO, N. C. et al. A inclusão escolar e o ensino de biologia: } \\
\text { a visão dos alunos }\end{array}$ & V ENEBIO (2014) \\
\hline
\end{tabular}

Continua. 
Continuação.

\begin{tabular}{|c|c|c|}
\hline 15 & $\begin{array}{l}\text { PEREIRA, R. I. dos S. Ser diferente, aprender diferente, viver } \\
\text { diferente: reflexões psicopedagógicas sobre a aprendizagem da } \\
\text { pessoa com cegueira }\end{array}$ & VII ENEBIO (2018) \\
\hline 16 & $\begin{array}{l}\text { VERASZTO, E. V. et al. Avaliação de concepções a respeito da } \\
\text { construção de conhecimentos científicos por cegos congênitos: } \\
\text { uma abordagem através do método de Análise de } \\
\text { Correspondência. }\end{array}$ & $\begin{array}{l}\text { uc., v. } 24, \text { n. } 4,2018 \text {, } \\
57\end{array}$ \\
\hline 17 & $\begin{array}{l}\text { DICKMAN, A. G.; FERREIRA, A. C. Ensino e aprendizagem de } \\
\text { Física a estudantes com deficiência visual: Desafios e } \\
\text { Perspectivas. }\end{array}$ & $\begin{array}{l}\text { Revista Brasileira de Pesquisa } \\
\text { em Educação em Ciências, v. } \\
8, \text { n. } 2,2011 \text {. }\end{array}$ \\
\hline 18 & $\begin{array}{l}\text { CAMARGO, E. P. de; NARDI, R.; CORREIA, J. N. A } \\
\text { comunicação como barreira à inclusão de alunos com deficiência } \\
\text { visual em aulas de Física Moderna. }\end{array}$ & $\begin{array}{l}\text { Revist } \\
\text { em Ed } \\
10, \text { n. }\end{array}$ \\
\hline 19 & $\begin{array}{l}\text { CAMARGO, E. P. de et al. Ensino de Física e deficiência visual: } \\
\text { atividades que abordam o conceito de aceleração da gravidade. }\end{array}$ & $\begin{array}{l}\text { Inve: } \\
\text { Ciên }\end{array}$ \\
\hline 20 & $\begin{array}{l}\text { CAMARGO, E. P. de et al. Concepções espontâneas de repouso } \\
\text { e movimento de uma pessoa deficiente visual total. }\end{array}$ & $\begin{array}{l}\text { Caderno Brasileiro de Ensino } \\
\text { de Física, v. 17, n. 3, 2000. }\end{array}$ \\
\hline 21 & $\begin{array}{l}\text { AZEVEDO, A. C.; SANTOS, A. C. F. Ciclos de aprendizagem } \\
\text { no ensino de física para deficientes visuais. }\end{array}$ & $\begin{array}{l}\text { Rev. Bras. Ensino Fís., v. 36, } \\
\text { n. } 4,2014\end{array}$ \\
\hline
\end{tabular}

Fonte: Elaborada pelos autores (2021).

Mesmo que essa categoria tenha emergido a partir de poucos trabalhos, pôde-se verificar que existem pesquisas que apresentam reflexões epistêmicas sobre a DV no ensino de Ciências. Por exemplo, o trabalho N2 buscou analisar as concepções dos estudantes cegos sobre a lua por meio de entrevista, concluindo, assim, que existe uma grande diversidade de concepções. O trabalho N3 também utiliza a entrevista para entender as percepções de alunos com DV sobre a educação ambiental, concluindo que eles têm uma visão naturalista sobre o tema.

Esses trabalhos demonstram que, mesmo que um estudante apresente algum tipo de DV, isso não o impede de perceber e criar uma concepção sobre as coisas que existem no universo, e de apresentar concepções mais avançadas do que aqueles que possuem todos os sentidos em plena funcionalidade e com condutas típicas. Neste sentido, percebese nos trabalhos da Tabela 10, que as categorias 1, 2 e 3 poderiam ser pensadas como "reflexões epistêmicas", ou seja, associá-las às instâncias sociais de produção, comunicação e avaliação do conhecimento, para este público em especial (Figura 1). Nessa perspectiva, sugere-se repensar o ensino de Ciências para alunos com DV dentro de um contexto escolar que pense em como desenvolver conhecimento relevante e as formas adequadas de construí-lo. 
DOI: https://doi.org/10.33238/ReBECEM.2021.v.5.n.2.27192

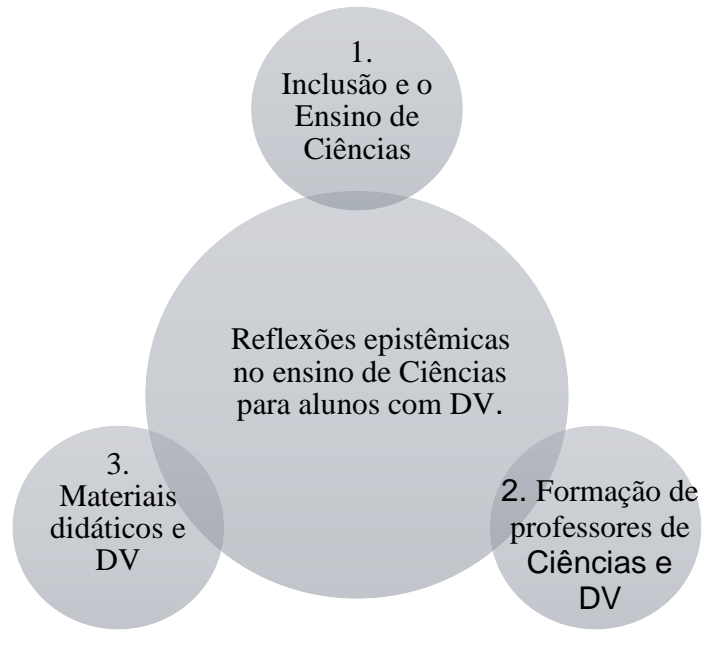

Figura 1. Relação das categorias 1, 2 e 3 com a categoria "reflexões epistêmicas no ensino de Ciências para alunos com DV".

Fonte: Elaborado pelos autores (2021).

Assim, podemos pensar em "reflexões epistêmicas", no contexto escolar de estudantes com DV, como o afastamento de um ensino individual e voltar-se para o processo social de construção do conhecimento desses alunos com outros sujeitos envolvidos (pais, comunidade escolar, professores, alunos com DV e todos os outros alunos), em que são valorizadas as ações, pensamentos, concepções e interações discursivas entre alunos e professor e de alunos entre si quando estes se envolvem na construção e na legitimação de conhecimentos.

Pensar em "reflexões epistêmicas", quando se fala e pesquisa sobre alunos com DV no ensino de Ciências, é um desafio que se faz necessário. Trata-se de pensar um ensino de Ciências mais inclusivo com alunos com DV, de modo que os sujeitos envolvidos no processo ensino-aprendizagem busquem traçar relações entre a construção de explicações, modelos explicativos ou argumentações com as ações/práticas desempenhadas em aulas de Ciências, em especial aquelas associadas à promoção de interações entre alunos, professor e os conhecimentos.

\section{Considerações Finais}

Essa pesquisa permitiu compreender que o ensino de Ciências para alunos com DV, mesmo com todas as políticas educacionais existentes, ainda apresenta algumas 
DOI: https://doi.org/10.33238/ReBECEM.2021.v.5.n.2.27192

limitações em lidar e, com isso, entende-se que a assistência aos alunos com deficiência deve visar a educação inclusiva no ensino regular.

Um dado evidenciado nesta pesquisa bibliográfica refere-se à formação dos professores de Ciências, que também aparece nos trabalhos de Paulon, Freitas e Pinho (2005), Oliveira (2018) e na Categoria 2 desta revisão. Foi possível verificar que existe uma dificuldade de trabalhar diferentes metodologias de ensino na formação inicial de muitos professores, bem como, estratégias e materiais didáticos voltados para os alunos cegos ou com baixa visão.

Também foi possível verificar que, muitas vezes, os professores de Ciências não conseguem ministrar suas aulas quando se tem alunos com DV na turma, uma vez que os docentes precisam ter meios para promover a inclusão deles e não conseguem realizá-lo.

O currículo de Ciências, tanto a BNCC, como as Diretrizes para a formação de professores da educação básica (BRASIL, 2019), precisam ser mais focados na educação inclusivista, visto que, através da presente pesquisa, foi possível observar que a maioria dos professores não está apto a trabalhar com alunos com deficiência, o que é tido como uma das principais dificuldades enfrentadas para que haja um ensino de Ciências de qualidade. Muitos deles ressaltam a falta de materiais didáticos adaptados, os quais trariam novas metodologias e melhorias às aulas, além de gerar uma inclusão tanto na sala de aula quanto na escola.

Dessa forma, as pesquisas no ensino de Ciências, voltadas para essa temática, ainda são bem escassas, porém, nos trabalhos analisados, constata-se uma crescente preocupação com a inclusão de alunos com DV, produção de materiais didáticos e a formação dos professores de Ciências para este público. O que se propõe neste trabalho, é que essas preocupações também estejam articuladas em "reflexões epistêmicas", ou seja, associá-las às instâncias sociais de produção, comunicação e avaliação do conhecimento, para os alunos com DV.

A presente pesquisa também contou com alguns empecilhos para ser elaborada, entre eles pode-se citar a dificuldade de encontrar trabalhos com a temática escolhida, além de que alguns anais nacionais de congressos não estão disponíveis na internet.

Diante do exposto, é interessante que se amplie estudos com essa temática, visto que a pesquisa em ensino de Ciências é uma área muito ampla, além de que, a reflexão sobre a inclusão no ensino, em particular no de Ciências, deve ser levado para o cotidiano dos alunos e das escolas, para que seja possível suprir as necessidades e sanar as dificuldades encontradas pelo ensino. 


\section{Referências}

BORGES, R. M. R.; SCHWARZ, V. O Papel dos jogos educativos no processo de qualificação de professores de Ciências. In: IV ENCONTRO IBERO-AMERICANO DE COLETIVOS ESCOLARES E REDES DE PROFESSORES QUE FAZEM INVESTIGAÇÃO NA SUA ESCOLA, 4. 2005, Rio Grande do Sul. Anais [..]. Rio Grande do Sul: UNIVATES, 2005. p. 1-7 Disponível em: <http://ensino.univates.br/ 4iberoamericano/trabalhos/trabalho074.pdf>. Acesso em: 20 fev. 2020.

BRASIL. Lei 9.394, de 20 de dezembro de 1996. Estabelece as diretrizes e bases da educação nacional. Diário Oficial da União, Brasília, DF, 23 dez. 1996. Disponível em:

<https://www.planalto.gov.br/ccivil_03/Leis/L9394.htm>. Acesso em: 30 jul. 2021.

BRASIL. Resolução CNE/CP No 1, de 18 de Fevereiro de 2002. Institui Diretrizes

Curriculares Nacionais para a Formação de Professores da Educação Básica, em nível superior, curso de licenciatura, de graduação plena. Brasília, 2002a. Disponível em:

<http://portal.mec.gov.br/seesp/arquivos/pdf/res1_2.pdf>. Acesso em: 30 jan. 2020.

BRASIL. Portaria no 2.678/02. Aprova o projeto da Grafia Braille para a Língua Portuguesa e recomenda o seu uso em todo o território nacional. Brasília, 2002b. Disponível em:

<http://www.fnde.gov.br/acesso-a-informacao/institucional/legislacao/item/3494-portaria-mecn\%C2\%BA-2678-de-24-de-setembro-de-2002>. Acesso em: 01 fev. 2020.

BRASIL. Ministério da Educação. Documento Subsidiário à Política de Inclusão. Brasília, 2005. Disponível em:

$<$ http://portal.mec.gov.br/seesp/arquivos/pdf/livro\%20educacao\%20inclusiva.pdf >. Acesso em: 01 fev. 2020.

BRASIL. Decreto Legislativo $\mathbf{n}^{0}$ 186, de 09 de julho de 2008. Aprova o texto da Convenção sobre os Direitos das Pessoas com Deficiência e de seu Protocolo Facultativo, assinados em Nova Iorque, em 30 de março de 2007. Disponível em:< http://pfdc.pgr.mpf.mp.br/atuacao-econteudos-de-apoio/legislacao/pessoa-deficiencia/Decreto_legislativo_186_2008 $>$. Acesso em: 20 dez. 2019.

BRASIL. Decreto $\mathbf{n}^{\circ}$ 6.949, de 25 de agosto de 2009. Promulga a Convenção Internacional sobre os Direitos das Pessoas com Deficiência e seu Protocolo Facultativo, assinados em Nova York, em 30 de março de 2007. Disponível em:

<https://presrepublica.jusbrasil.com.br/legislacao/818741/decreto-6949-09>. Acesso em: 18 dez. 2019.

BRASIL. Convenção sobre o Direito das pessoas com deficiência. Brasília, 2007. Disponível em: 〈https://www.ucs.br/site/midia/arquivos/convencao.pdf>. Acesso em: 15 jan. 2020 
DOI: https://doi.org/10.33238/ReBECEM.2021.v.5.n.2.27192

BRASIL/SEB/MEC. Base Nacional Comum Curricular. SEB/MEC: Brasília, 2018.

Disponível em:

<http://basenacionalcomum.mec.gov.br/images/BNCC_EI_EF_110518_versaofinal_site.pdf 〉.

Acesso em: 01 nov. 2019.

BRASIL. Ministério da Educação. Resolução CNE/CP N ${ }^{\circ}$ 2, de 20 de dezembro de 2019. Define as Diretrizes Curriculares Nacionais para a Formação Inicial de Professores para a Educação Básica e institui a Base Nacional Comum para a Formação Inicial de Professores da Educação Básica (BNC-Formação). Diário Oficial da União, Brasília, 23 dez. 2019, Seção 1, pp. 115-119. Disponível em:

<http://portal.mec.gov.br/index.php?option=com_docman\&view=download\&alias=135951rcp002-19\&category_slug=dezembro-2019-pdf\&Itemid=30192>. Acesso em: 31 jan. 2020.

GONÇALVES, F. P.; REGIANI, A. M.; AURAS, S. R.; SILVEIRA, T. S.; COELHO, J. C.; HOBMEIR, A.K. T. A educação inclusiva na formação de professores e no ensino de química: a deficiência visual em debate. Química nova na escola, São Paulo, v. 35, n. 4, p. 264-271, 2013.

LIMA, M. C. B.; CASTRO, G. F. de. A formação inicial de professores de física: a questão de alunos com deficiência visual no ensino regular. Revista Ciência \& Educação, Bauru, v. 18, n. 1, p. 81-98, 2012.

LÜDKE, M.; ANDRÉ, M. E. D. A. Pesquisa em educação: abordagens qualitativas. 2. ed. São Paulo: E.P.U., 1986.

MORAES, R.; GALIAZZI, M. C. Análise Textual Discursiva. 3. ed. Ijuí; UNIJUÍ, 2011.

OLIVEIRA, F. I. W.; BIZ, V. A.; FREIRE, M. Processo de inclusão de alunos deficientes visuais na rede regular de ensino: confecção e utilização de recursos didáticos adaptados. Núcleo de Ensino UNESP: Marília, v. 1, n.1, p. 445-454, 2003.

OLIVEIRA, A. A. Um olhar sobre o ensino de Ciências e Biologia para alunos deficientes visuais. 2018. 83f. Dissertação (Mestrado em Ensino da Educação Básica) - Universidade Federal do Espírito Santo, São Mateus, 2018.

PACHECO, J.; EGGERTSDÓTTIR, R.; MARINÓSSON, G. L. Caminhos para a inclusão: um guia para o aprimoramento da equipe escolar. 1. ed. São Paulo: Artmed, 2007.

PACHECO, R. V.; COSTAS, F. A. T. O processo de inclusão de acadêmicos com necessidades educacionais especiais na Universidade Federal de Santa Maria. Revista Educação Especial. Santa Maria, v. 7, n. 27, p. 151-167, 2006.

PROFETA, M. S. A inclusão do aluno com deficiência visual no ensino regular. In: MASINI, E. F. S. A pessoa com deficiência visual: um livro para educadores. 1. ed. São Paulo: Vetor, 2007. p. 209-236. 
QUADROS, L.; NOVAES, T.; LIBARDI, D.; RABBI, M.A.; FERRACIOLI, L. Construção de tabela periódica e modelo físico do átomo para pessoas com deficiência visual. IN: ENCONTRO NACIONAL DE PESQUISA EM EDUCAÇÃO EM CIÊNCIAS (ENPEC), 8 , 2011, Campinas. Anais [...]. Campinas: Unicamp, 2011. p. 01-11. Disponível em: <http://abrapecnet.org.br/atas_enpec/viiienpec/resumos/R1482-3.pdf>. Acesso em: $01 \mathrm{fev}$. 2020.

REILY, L. Escola Inclusiva: linguagem e mediação. 1. ed. Campinas: Papirus, 2004.

SÁ, E. D.; CAMPOS, I. M.; SILVA, M. B. C. Atendimento Educacional Especializado: Deficiência Visual. 1. ed. Brasília: Gráfica e Editora Cromos, 2007.

SEED. Secretaria de Estado da Educação, Deficiência Visual. Disponível em: http://www.educadores.diaadia.pr.gov.br/modules/conteudo/conteudo.php?conteudo=686. Acesso em: 22 mar. 2020.

SILVA, T. A.; LANDIM, M. F.; SOUZA, V. R. M. A utilização de recursos didáticos no processo de ensino aprendizagem de ciências de alunos com deficiência visual. Revista electrónica de Enseñanza de las Ciencias, Uvigo, v. 13, n. 1, p. 32-47, 2014

SILVA, A. P. M. S.; ARRUDA, A. L. M. M. O Papel do Professor diante da Inclusão escolar. Revista Eletrônica Saberes da Educação, São Roque, v. 5, n. 1, p. 1-29. 2014

UNESCO. Programa en prol de la ciencia: marco general de acción. IN: CONFERENCIA MUNDIAL SOBRE LA CIENCIA, 1. 1999, Budepeste. Anais [...]. Budapeste: Unesco, 1999. p. 33-35 Disponível em: 〈http://www.unesco.org/science/wcs/esp/marco_accion_s.htm>. Acesso em: $28 \mathrm{dez} 2019$.

Recebido em: 03 de abril de 2021

Aceito em: 17 de julho de 2021 